\title{
EFEITO DA MAÇÃ GALA (Malus domestica Bork) NA LIPIDEMIA DE RATOS HIPERCOLESTEROLÊMICOS
}

\author{
FABIANA CURTI
}

Dissertação apresentada à Escola Superior de Agricultura "Luiz de Queiroz", Universidade de São Paulo, para obtenção do título de Mestre em Ciências, Área de Concentração: Ciência e Tecnologia de Alimentos.

P I R A C I C A B A

Estado de São Paulo - Brasil

Novembro - 2003 


\title{
EFEITO DA MAÇÃ GALA (Malus domestica Bork) NA LIPIDEMIA DE RATOS HIPERCOLESTEROLÊMICOS
}

\section{FABIANA CURTI}

Nutricionista

Orientadora: Profa. Dra. JOCELEM MASTRODI SALGADO

\author{
Dissertação apresentada à Escola Superior de \\ Agricultura "Luiz de Queiroz", Universidade de São \\ Paulo, para obtenção do título de Mestre em Ciências, \\ Área de Concentração: Ciência e Tecnologia de \\ Alimentos
}

P I R A C I C A B A

Estado de São Paulo - Brasil

Novembro - 2003 


\section{Dados Internacionais de Catalogação na Publicação (CIP) DIVSÃO DE BIBLIOTECA E DOCUMENTAÇÃO - ESALQ/USP}

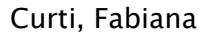

Dissertação (mestrado) - - Escola Superior de Agricultura Luiz de Queiroz, 2003. Bibliografia.

1. Análise de alimentos 2. Bioquímica 3. Dietoterapia 4. Doenças cardiovasculares 5. Hipercolesterolemia 6. Maça 7. Prevenção de doença I. Título

CDD 664.80411

\section{“Permitida a cópia total ou parcial deste documento, desde que citada a fonte - O autor"}


Aos meus carinhosos pais, Maria Amélia Cairo Curti e Roberto Curti. À minhas queridas irmãs, Simone Curti e Margarida Curti. À minha querida avozinha Margarida Cairo. E ao meu amor, Daniel Bruno Beluti, dedico e ofereço... 


\section{AGRADECIMENTOS}

À Deus, pela vida, pela força inata de cada ser humano e pelo amor.

À Jesus, pela paz.

À Escola Superior de Agricultura "Luiz de Queiroz", principalmente ao Departamento de Agroindústria, Alimentos e Nutrição, pela oportunidade e pelos ensinamentos.

À CAPES (Coordenadoria de Aperfeiçoamento do Pessoal de Ensino Superior), pelo auxílio financeiro.

À Profa. Dra. Jocelem Mastrodi Salgado, pela orientação e pela oportunidade de crescer como pessoa.

À toda a minha família, em especial à Maria Amélia Cairo Curti, pelos ouvidos amigos; ao Roberto Curti, pelas palavras de segurança e constante presença; à Margarida Cairo pelas orações e à Simone Curti e Margarida Curti pela dedicação e por serem tão prestativas em tudo.

Ao meu amor Daniel Bruno Beluti, pelo carinho, por sempre ser tão atencioso em todos os momentos e pelas valiosas palavras de otimismo, incentivo e força e à sua família, em especial à Maria do Carmo de Carvalho Beluti, pelo constante incentivo de coragem e pelas orações.

Aos meus tios, Marco Antonio Cairo e Sylvia Maria Bruce Cairo, e ao Prof. Dr. Mario Massayuki Inomoto pela confiança.

Às técnicas Maria de Lourdes Perin Storer e Débora Niero Mansi, pelo auxílio nas análises laboratoriais e pela amizade e ajuda.

À secretária Raquel Iracema da Silva Ermida pelas palavras de constante incentivo, amizade e força. 
Aos professores: Dra. Marisa A. R. d'Arce, Dra. Solange Guidolin Canniatti Brazaca e Dr. Luiz Eduardo Gutierrez, pelas valiosas sugestões no momento da qualificação.

À Profa. Dra. Marinéia de Lara Haddad, pela colaboração nas análises estatísticas.

À Profa. Dra. Valéria Pascoal, pelo carinho e confiança.

Às bibliotecárias Beatriz Helena Giongo e Midian Gustinelli, por serem tão prestativas nas pesquisas bibliográficas.

Aos bibliotecários do COMUT, Silvio e Vilma, pelo auxílio.

À secretária Regina Lúcia de Mello Lourenço, pela constante compreensão, paciência e ajuda.

A todos os funcionários do Departamento, especialmente ao Luiz Carlos Rodrigues, pelo apoio técnico.

Às amigas Daniela Andrade Medeiros, Eloise Santucci Ribeiro, Romilda Maria de Arruda Germano, Débora Niero Mansi, Margarida Curti e Simone Curti, pela revisão e auxílio na elaboração desse trabalho.

Ao "Super varejão dois irmão", pelo fornecimento das maçãs.

Ao corpo técnico do Departamento de Química pelas análises dos minerais.

A todos os meus colegas da pós-graduação, pelos momentos de companheirismo, em especial à Marielen de Lima Silva.

E a todos que de alguma forma colaboraram para a elaboração dessa dissertação. 


\section{SUMÁRIO}

\begin{tabular}{|c|c|}
\hline & Página \\
\hline LISTA DE FIGURAS.. & viii \\
\hline LISTA DE TABELAS. & ix \\
\hline RESUMO.. & $\mathrm{xi}$ \\
\hline 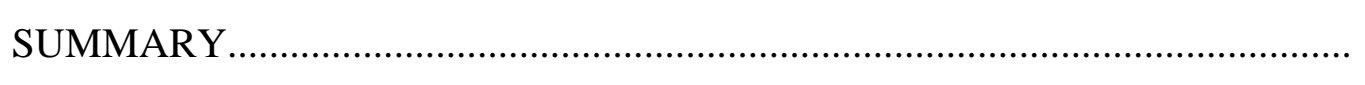 & xiii \\
\hline 1 INTRODUÇÃO............................... & 1 \\
\hline 2 REVISÃO DE LITERATURA... & 6 \\
\hline 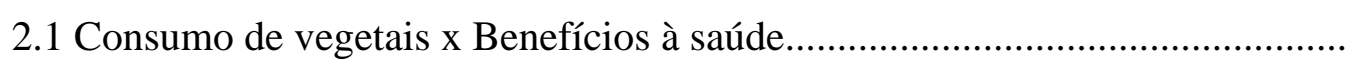 & 7 \\
\hline 2.2 Fitoquímicos e alimentos com efeito hipocolesterolêmico............................... & 11 \\
\hline 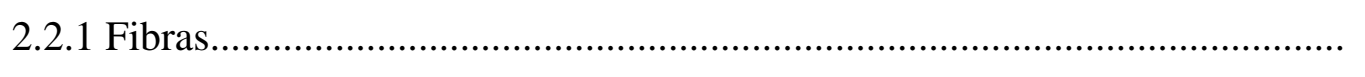 & 11 \\
\hline 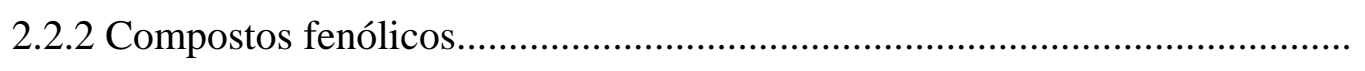 & 13 \\
\hline 2.2.3 Minerais...... & 15 \\
\hline 2.3 Maçã : seus nutrientes e componentes ativos.... & 16 \\
\hline 2.4 Efeitos benéficos no consumo de maçã na lipidemia.......... & 18 \\
\hline 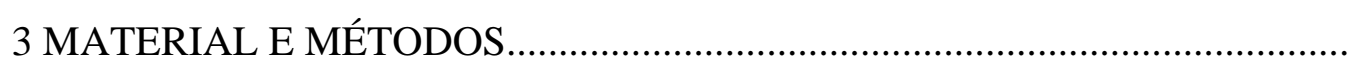 & 21 \\
\hline 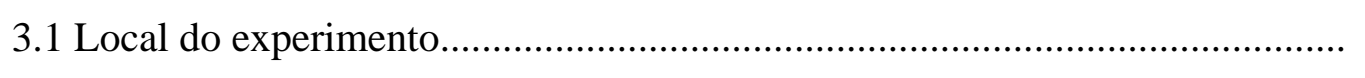 & 21 \\
\hline 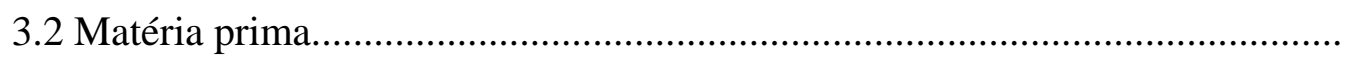 & 21 \\
\hline 3.3 Análises químicas da maçã.......... & 21 \\
\hline 3.3.1 Composição centesimal da maçã.. & 22 \\
\hline 3.3.2 Determinação de vitamina C...... & 22 \\
\hline 3.3.3 Determinação de taninos e compostos fenólicos......... & 22 \\
\hline 3.4 Ensaio biológico.... & $2 \angle$ \\
\hline 4.1 Dieta & \\
\hline
\end{tabular}




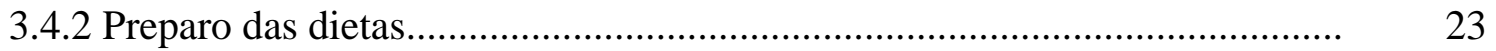

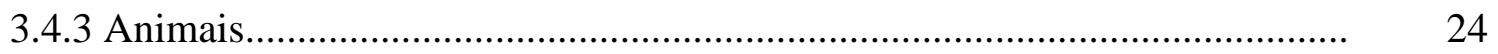

3.4.4 Coleta de sangue/fígado e análises bioquímicas............................................. 24

3.4.5 Coleta de fezes e análise.............................................................................. 25

3.4.6 Análise estatística....................................................................................... 25

4 RESULTADOS E DISCUSSÃO.............................................................. 27

4.1 Análise química do colesterol alimentar........................................................... 27

4.2 Análises químicas da maçã.............................................................................. 27

4.2.1 Composição centesimal............................................................................... 27

4.2.2 Minerais............................................................................................. 29

4.2.3 Vitamina C.......................................................................................... 31

4.2.4 Compostos fenólicos.............................................................................. 32

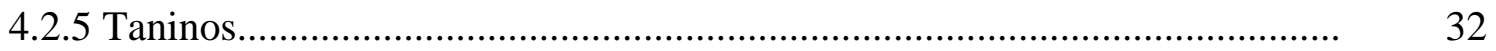

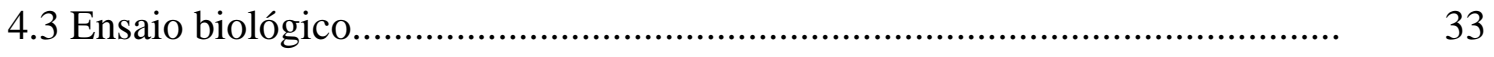

4.3.1 Consumo alimentar e ganho de peso......................................................... 33

4.3.2 Análises bioquímicas.................................................................................. 38

4.3.2.1 Colesterol total...................................................................................... 38

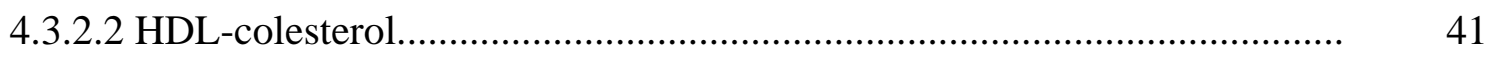

4.3.2.3 LDL-colesterol......................................................................................

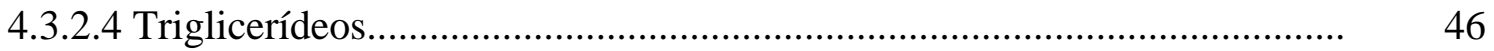

4.3.2.5 Colesterol hepático.................................................................................... 49

4.3.2.6 Colesterol excretado........................................................................... 52

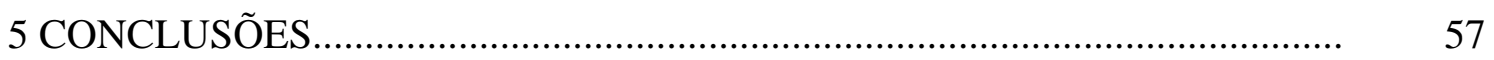

5.1 Considerações finais..................................................................................... 5

REFERÊNCIAS BIBLIOGRÁFICAS.............................................................. 59 


\section{LISTA DE FIGURAS}

Página

1 Consumo de dieta (g) e ganho de peso (g) em quinzenas dos grupos controle (a), 5\% de maçã (b), 15\% de maçã (c) e 25\% de maçã (d) no tempo 30 .

2 Consumo de dieta (g) e ganho de peso (g) em quinzenas dos grupos controle (a), 5\% de maçã (b), $15 \%$ de maçã (c) e 25\% de maçã (d) no tempo 60.

3 Níveis séricos de colesterol total $(\mathrm{mg} / \mathrm{dL})$ em ratos machos Wistar durante

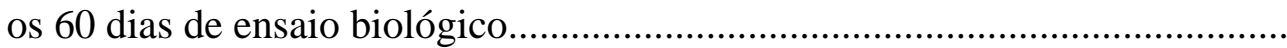

4 Níveis séricos de HDL-colesterol (mg/dL) em ratos machos Wistar durante

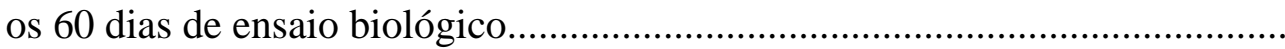

5 Níveis séricos de LDL-colesterol (mg/dL) em ratos machos Wistar durante os 60 dias de ensaio biológico.

6 Níveis séricos de triglicerídeos (mg/dL) em ratos machos Wistar durante os 60 dias de ensaio biológico.

7 Níveis séricos de colesterol hepático (mg/dL) em ratos machos Wistar

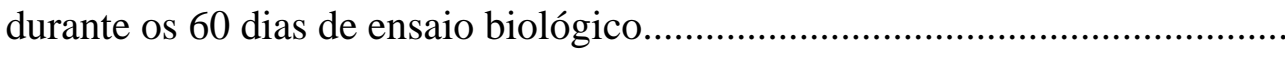

8 Níveis séricos de colesterol excretado (mg/dL) em ratos machos Wistar durante os 60 dias de ensaio biológico 


\section{LISTA DE TABELAS}

Página

1 Composição das dietas controle e suplementadas com maçã Gala.................. 23

2 Composição centesimal da maçã variedade Gala........................................... 28

3 Teor de minerais da maçã variedade Gala................................................... 30

4 Consumo de dieta (g) e ganho de peso (g) médios dos animais do tempo 30 e 60 dias.

5 Concentração plasmática de colesterol total aos 30 e 60 dias em animais que receberam os tratamentos C.C. (controle caseína), 5\% de maçã, 15\% de maçã e 25\% de maçã......................................................................................

6 Concentração plasmática de HDL-C aos 30 e 60 dias em animais que receberam os tratamentos C.C. (controle caseína), 5\% de maçã, 15\% de maçã e $25 \%$ de maçã........................................................................................

7 Concentração plasmática de LDL-C aos 30 e 60 dias em animais que receberam os tratamentos C.C. (controle caseína), 5\% de maçã, 15\% de maçã e 25\% de maçã......................................................................................

8 Concentração plasmática de triglicerídeos aos 30 e 60 dias em animais que receberam os tratamentos C.C. (controle caseína), 5\% de maçã, 15\% de maçã e 25\% de maçã.........................................................................................

9 Concentração plasmática de colesterol hepático aos 30 e 60 dias em animais que receberam os tratamentos C.C. (controle caseína), 5\% de maçã, 15\% de

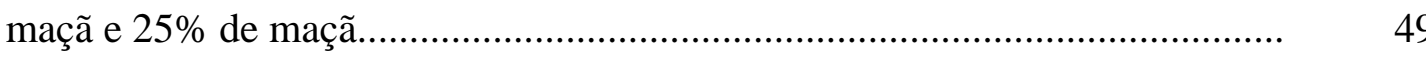

10 Análise de variância para colesterol hepático................................................ 51 
11 Teste de Tukey para médias de tratamento no nível de colesterol

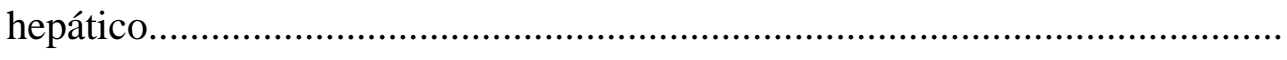

12 Concentração plasmática de colesterol excretado aos 30 e 60 dias em animais que receberam os tratamentos C.C. (controle caseína), 5\% de maçã, 15\% de maçã e 25\% de maçã..................................................................................

13 Análise de variância para colesterol excretado................................................. 54

14 Teste de Tukey para médias de tratamento no nível de colesterol

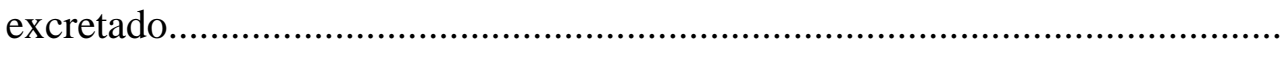




\section{EFEITO DA MAÇÃ GALA (Malus domestica Borkh) NA LIPIDEMIA DE RATOS HIPERCOLESTEROLÊMICOS}

Autora: FABIANA CURTI

Orientadora: Profa. Dra. JOCELEM MASTRODI SALGADO

\section{RESUMO}

Hábitos de vida saudáveis e uma dieta balanceada aliados ao alto consumo de frutas e vegetais, estão associados à prevenção de doenças e à manutenção da saúde. A maçã possui em sua composição compostos bioativos que podem agir na prevenção e no controle das dislipidemias. Tendo em vista a preocupação da Saúde Pública em encontrar uma fonte alternativa na redução das doenças cardiovasculares, esse trabalho teve como objetivo analisar a composição química da maçã, variedade Gala, e estudar os efeitos do seu consumo no ganho de peso, consumo alimentar, níveis sanguíneos de colesterol total, HDL-C, LDL-C, triglicerídeos, colesterol hepático e colesterol excretado em ratos Wistar hipercolesterolêmicos. Foram utilizados 6 animais em cada grupo de tratamento (controle, 5\%, 15\% e 25\% de maçã na dieta) durante 30 e 60 dias. Foi observado neste estudo, quanto a composição centesimal da maçã, que uma maçã (200g), é capaz de fornecer 14,5\% das recomendações de fibras totais e 55\% de vitamina C, além de quantidades consideráveis de compostos fenólicos $(0,38 \mathrm{~g} / 100 \mathrm{~g}$ em base fresca) e tanino (0,16g/100g em base fresca). No ensaio biológico, os animais de ambos os tempos, apresentaram uma redução não significativa no ganho de peso e no consumo de dieta com o aumento das concentrações de maçã. Ao final de 30 dias, todas as dietas proporcionaram uma redução significativa ( $\mathrm{p} \leq 0,05)$ nos níveis de triglicerídeos comparativamente ao grupo controle e não significativa com relação aos 
níveis de HDL-C. As dietas com 15\% e 25\% de maçã mostraram reduções significativas nos níveis sanguíneos de colesterol total e LDL-C e um aumento no teor de colesterol excretado em relação ao grupo controle. A dieta com 25\% de maçã promoveu uma redução significativa nos níveis de colesterol hepático em comparação ao grupo controle. Aos 60 dias, os níveis sanguíneos de colesterol total, LDL-C, HDL-C e triglicerídeos de ratos alimentados com as dietas 5\%, 15\% e 25\% de maçã foram semelhantes ao grupo controle.A partir desses resultados, pode-se concluir que a maçã Gala é um potente alimento no controle dirigido das dislipidemias em ratos. Uma dieta rica em verduras, legumes e frutas, inclusive a maçã, associado a um estilo de vida saudável, ao longo do tempo, podem ser considerados fundamentais na prevenção e redução do risco de doenças, principalmente as cardiovasculares. 


\section{EFFECT OF GALA APPLE (Malus domestica Borkh) IN THE LIPIDEMIA OF THE HYPERLIPIDEMICS RATS}

Author: FABIANA CURTI

Adviser: Phd. Prof. JOCELEM MASTRODI SALGADO

\section{SUMMARY}

Healthy life habits and an equilibrate diet, associated with a high fruit and vegetable intake, are joined with the prevention of diseases and health maintenance. The apple has in its composition bioactives compounds that can help in the prevention and control of hyperlipidemia. With the worry of Public Health to find an alternative source in the reduction of the cardiovasculars diseases, the objective of this work was to analyse the chemical composition of the Gala apple and to study the effects of its consumption in the gain of weigh, food intake, seric levels of total cholesterol, HDL-C, LDL-C, triglycerides, hepatic cholesterol and feces cholesterol in hypercholesterolemics Wistar rats. Six animals were distributed in each treatments (control, 5\%, 15\% and 25\% apple diet) during 30 and 60 days. This study showed that one apple (200g) can provide 14,5\% of the total fiber and $55 \%$ of the vitamin $\mathrm{C}$ within the recommendation, besides considerable quantities of phenolic compounds $(0,38 \mathrm{~g} / 100 \mathrm{~g}$ wet weigh) and tannins (0,16 g/100g wet weigh). In the biological assay all the animals showed a non significative reduction in the gain of weigh and food intake with the increase of apple concentrations in the diets. At the end of 30 days, all the diets provided a significative reduction in the levels of tryglicerides comparable to the control group and non significative in relation to HDL-C levels. The 15\% and 25\% apple diets showed significatives reductions in the seric levels of total cholesterol and LDL-C and an 
increase in the level of feces cholesterol in relation to the control group. The $25 \%$ apple diet provided a significative reduction in the hepatic cholesterol levels comparable to the control group. After 60 days, the seric levels of total cholesterol, LDL-C, HDL-C and tryglicerides in rats fed with 5\%, 15\% and 25\% apple diets were alike to the control group. These results confirm the importance of the Gala apple in the rats hyperlipidemia control. A diet rich in vegetables and fruits, including apple, associated with a healthy life habits, along the time, can be considered in the prevention and reduction against the risk of disease, mainly, the cardiovascular ones. 


\section{INTRODUÇÃO}

A alimentação é um dos principais fatores determinantes da saúde humana. Sendo assim, as pesquisas sobre os hábitos alimentares e as propriedades dos alimentos têm aumentado, visando fornecer uma proteção adicional na redução do risco de doenças crônicas, como as do aparelho circulatório (Bertasso, 2000).

O panorama nacional das doenças cardiovasculares prevê uma verdadeira epidemia com conseqüências para a saúde pública, devido a tendência de elevação na sua mortalidade em países em desenvolvimento, dentre os quais o Brasil é um dos representantes (Santos, 2001).

Segundo Caramelli (2002), as doenças do aparelho circulatório estão em primeiro lugar entre as causas de morte no Brasil, com quase um terço de todas as causas e representam um enorme ônus financeiro para o país. Dentro do grupo das doenças circulatórias, o infarto do miocárdio e as doenças cerebrovasculares são aquelas com maiores índices de mortalidade. Com o intuito de se reverter esse quadro, é necessário intervir de maneira concreta no controle dos chamados fatores de risco. Quanto maior a intensidade e o tempo de exposição ao fator de risco, maior a possibilidade de se desenvolver a doença, por outro lado, o controle ou a eliminação do fator de risco reduz a probabilidade do surgimento de novos casos.

Os fatores de risco podem ser classificados quanto à possibilidade de serem ou não modificáveis por mudanças no estilo de vida e/ou medicamentosa. Os não modificáveis são: idade, sexo e história familiar positiva para doença cardiovascular, e os modificáveis são: hipercolesterolemia (excesso de colesterol no sangue), nível de HDL-C (High Density Lipoprotein-Cholesterol) menor que $35 \mathrm{mg} / \mathrm{dL}$, diabetes, tabagismo, sedentarismo, hipertensão arterial, obesidade e estresse (Vale \& Martinez, 2000). 
O papel das dislipidemias, termo usado para definir alterações dos níveis lipídicos no sangue, no desenvolvimento das doenças cardiovasculares tem sido estabelecido por evidências epidemiológicas, clínicas, genéticas e de estudos em animais de laboratório. Vários estudos indicam que baixos níveis de HDL-C e altos níveis de colesterol total, LDL-C (Low Density Lipoprotein-Cholesterol) e VLDL-C (Very Low Density Lipoprotein-Cholesterol) apresentam uma relação com doenças cerebrovasculares e com o aparecimento de ateroma (Moriguchi, s.d.).

Ross (1999) também menciona a hipercolesterolemia como um dos principais fatores de risco para a formação de ateroma. A aterosclerose, que é considerada a principal causa de morte na civilização ocidental, consiste de um processo multifatorial patológico na formação de ateroma, iniciando-se geralmente na infância e produzindo manifestações clínicas na idade adulta média e/ou tardia.

De acordo com Brasil (2002), mais de 30\% da população brasileira apresenta altos níveis de colesterol (maior que $200 \mathrm{mg} / \mathrm{dL}$ ), um dado preocupante, já que estudos mostram que taxas acima de $240 \mathrm{mg} / \mathrm{dL}$ de colesterol duplicam o risco de sofrer um ataque cardíaco.

Segundo Moriguchi (s.d.), deve-se conhecer também o nível sérico das frações do colesterol, pois na prática clínica, sabe-se que apenas a medida do colesterol total não representa o melhor indicador do risco de doenças cardiovasculares.

$\mathrm{O}$ alto consumo de alimentos ricos em colesterol e gorduras, principalmente a saturada, e o baixo consumo de alimentos fontes de substâncias antioxidantes e fibras, resultam em um teor sanguíneo elevado de colesterol sérico e suas frações representando um dos principais fatores de risco para a doença cardiovascular (Mc namara, 2000).

O controle de doenças cardiovasculares, em pacientes com dislipidemias, pode ser feito com o auxílio de medicamentos, programas de atividade física e através da terapia nutricional, necessitando do apoio de vários profissionais da saúde para uma melhor conduta terapêutica, uma vez que existe uma sinergia entre os fatores de risco. Para isso, os pacientes devem estar cientes sobre a importância da adesão da dieta, a necessidade na mudança do estilo de vida e de comportamento, devendo ser acompanhados principalmente por nutricionistas. Para melhores resultados, a dieta para 
hipercolesterolemia deverá ser semelhante à habitual, além de nutricionalmente adequada e agradável ao paladar. O paciente deverá receber também orientações relacionadas à seleção, quantidades, técnicas de preparo e substituição dos alimentos (Santos, 2001).

A dieta é também a melhor conduta quando se deseja fazer a prevenção das doenças cardiovasculares e de outras doenças como por exemplo o câncer (Lampe, 1999). De acordo com Mazur et al. (1998), os fatores dietéticos são extremamente importantes e devem sempre ser considerados ao se determinar os riscos para essas doenças.

A III diretriz brasileira sobre dislipidemias e diretriz de prevenção da aterosclerose do Departamento de Aterosclerose da Sociedade Brasileira de Cardiologia sugere que, uma alimentação rica em frutas e vegetais diversificados seja adotada por todas as pessoas, fornecendo doses apropriadas de substâncias antioxidantes, a fim de prevenir ou reduzir o desenvolvimento da doença aterosclerótica, contribuindo para a manutenção da saúde (Santos, 2001).

Maus hábitos alimentares, principalmente aqueles que acarretam a obesidade infantil, geram problemas de saúde imediatos e a longo prazo. Segundo Turano \& Almeida (1999), a formação dos hábitos alimentares efetiva-se pela freqüência do consumo de certos alimentos, tendo início desde o primeiro ano de vida, criando a exigência do paladar, envolvendo ainda, um forte contingente de sentimentos regionalistas e recordações afetivas ligadas à família e ao meio social. Logo, nota-se a dificuldade em modificá-los, porque além de constituírem parte da cultura, implicam solidariedade ao grupo social a que o indivíduo pertence, visto que, são transmitidos de geração em geração.

Um estudo que analisou a quantidade e a qualidade de produtos alimentícios veiculados por canais abertos da televisão brasileira, observou que, de todos os anúncios de três principais redes da televisão durante 12 horas diárias por 2 anos, a maioria (22,47\%) é sobre alimentos, sendo $57,8 \%$ desses, pertencentes ao grupo das gorduras, óleos, açúcares e doces, foi observado também a completa ausência de frutas e outros vegetais. De acordo com a pesquisa, isso contribui para uma mudança nos hábitos 
alimentares de crianças e jovens, já que essa faixa etária passa um tempo maior assistindo à televisão (Almeida et al., 2002).

Esse tipo de publicidade baseado em marketing exerce uma maior influência no comportamento alimentar da população do que as afirmações de profissionais especializados, pois esses alimentos por serem mais atraentes, são escolhidos preferencialmente (Turano \& Almeida, 1999).

Diante desse quadro, em que uma alimentação nutricionalmente desequilibrada é uma das responsáveis por um aumento das doenças cardiovasculares, tornam-se necessárias medidas preventivas no sentido de alterar o padrão de hábitos alimentares, aliadas às políticas públicas de educação nutricional (Almeida et al., 2002).

Harker et al. (2003) relataram que, a chave para o consumo de frutas depende de fatores como a promoção da saúde e a praticidade. Maçãs e bananas são tidas como frutas preferidas por serem mais práticas do que o kiwi e a laranja para serem consumidas em viagens, no trabalho e até mesmo em casa. Acredita-se que um processo de conscientização do poder benéfico das frutas, em geral, pode aumentar a venda desses alimentos e, para isso, torna-se necessário a condução de estudos experimentais e clínicos sérios, que demonstrem cientificamente, através de biomarcadores confiáveis, os benefícios preconizados.

Carvalho (1998), em um levantamento de campo realizado em cem unidades domiciliares na cidade de Piracicaba em 1995, através de entrevistas estruturadas, realizou um estudo centrado no processo de tomada de decisão de consumo, em relação às frutas in natura, com foco domiciliar. Esse estudo também indicou a maçã, assim como Harker et al. (2003), como uma das frutas, além da laranja e banana, efetivamente preferidas e conseqüentemente compradas pelos consumidores. E que, preocupações com a saúde, além da presença de resíduos químicos provenientes dos agrotóxicos e a influência sociocultural podem interferir no consumo de frutas.

Segundo Instituto Brasileiro de Geografia e Estatística (IBGE) a maçã representa apenas 7,2\% do consumo entre todas as frutas no Brasil (IBGE, 1998), esse baixo índice pode-se atribuir, principalmente, pela falta de hábito de consumo da população (Jorge et al., 1998). 
Os países de maior produção de maçã são a China e os EUA, sendo que o Brasil ocupa o $8^{\circ}$ lugar em produção mundial (FNP consultoria \& comércio, 2002). No entanto, no ciclo 2001/2002, o Brasil teve um aumento de 20\% (previsão feita em agosto/2002) na sua participação mundial, com relação ao ciclo 2000/2001, mostrando uma tendência de aumento na produção da fruta (FNP consultoria \& agroinformativos, 2003).

Segundo dados do agrianual, FNP consultoria \& comércio (2002), o aumento na produção de maçãs é preocupante no mercado nacional e mundial, visto que a oferta tem superado a demanda. No congresso da WAPA (World Apple and Pear Association) foram discutidos passos para tirar o setor da crise, pois até os países do Hemisfério Norte têm vendido maçãs e pêras a preços abaixo de seu custo de produção. No caso do mercado brasileiro, o caminho é aumentar a qualidade, reorganizar a oferta e desenvolver ações para aumentar o consumo. Uma dessas ações está no desenvolvimento de estudos com a fruta, no sentido de se comprovar seus efeitos benéficos para a saúde, estabelecendo alegações funcionais e/ou de saúde, que poderão ser utilizados no momento da venda do alimento ao consumidor.

Diante do exposto, e considerando que poucas pesquisas no âmbito nacional têm avaliado o potencial da maçã em prevenir e controlar doenças cardiovasculares, o presente trabalho teve como objetivo, analisar a composição química da maçã variedade Gala (Malus domestica Borkh) e estudar os efeitos de diferentes concentrações de maçã no consumo alimentar, no ganho de peso, nos níveis de colesterol sangüíneo e frações, colesterol hepático e excretado em animais experimentais hipercolesterolêmicos. 


\section{REVISÃO DE LITERATURA}

A maçã da variedade Gala é originária na Nova Zelândia. Os frutos apresentamse com formato redondo e alongado, com coloração vermelho-clara e aparência muito bonita. O peso médio do fruto varia de $150 \mathrm{~g}$ a $200 \mathrm{~g}$ com boa proporção de açúcares e ácidos (Ushirozawa, 1978). Quanto ao armazenamento é uma variedade com boa resistência (Yuri \& Martines Filho, 1999). A maçã Gala, por ter alto teor de umidade, ganhou a concorrência com a maçã Red Delicious, importada da Argentina, que é considerada mais "farinhenta" (Gonçalves et al., 1996).

Atualmente, segundo Petri (2003) ${ }^{1}$, as variedades Gala e Fuji representam 95\% da produção de maçãs brasileiras, sendo que apenas a cultivar Gala é responsável por 48\% dessa produção. Gonçalves et al. (1996) e Yuri \& Martines Filho (1999) também mencionam a hegemonia da variedade Gala tanto no consumo interno como na exportação.

Em um estudo que avaliou quatro variedades de maçã (Gala, Fuji, Golden Delicious e Granny Smith) quanto à textura (suculência e consistência), sabor e odor (características definidas pelo estudo como atributos importantes na qualidade de maçãs in natura), foi concluído que a variedade Gala apresenta maior intensidade de odor característico e, com relação à qualidade geral, a maçã Gala assim como a Granny Smith, obtiveram os melhores resultados (Treptow et al., 1995). Da mesma maneira, Fontoura \& Freitas (1993) estudando as características sensoriais de algumas variedades e maçãs cultivadas no Brasil, foi observado que, assim como o estudo anterior, a maçã Gala apresentou as melhores características externas, com relação à cor, aparência e aroma.

\footnotetext{
${ }^{1}$ PETRI, J.L. Maçã. petri@epagri.rct-sc.br (16 jul. 2003)
} 
A importância comercial da maçã pode ser explicada por sua disposição no mercado durante todo o ano e as várias formas de consumo: fresca, sucos, sidra, compotas (Aprikian et al., 2001), doces, vinagre, geléias, molhos e purês para acompanhar carnes, além da incorporação de farinhas de maçã em bolos, pães e biscoitos a fim de enriquecer esses alimentos, agregando valor aos produtos.

O bagaço é caracterizado como o principal sub-produto gerado pelas indústrias de processamento do fruto para obtenção de produtos, principalmente sucos. Protzek et al. (1998a) estudaram o aproveitamento do bagaço da maçã para produção de biscoitos ricos em fibras. Os pesquisadores concluíram que a farinha, proveniente do bagaço da maçã, mostrou-se ser um ingrediente alimentício de elevado potencial como fonte de fibras alimentares, e os biscoitos apresentaram boa aceitação entre os consumidores.

Na panificação, a farinha de maçã também mostrou ser um ingrediente em potencial para enriquecimento de produtos com fibra alimentar, em um estudo que teve como objetivo a elaboração de pães ricos em fibras utilizando como fonte o bagaço de maçã seco. Concluiu-se que os pães com melhor aceitação foram aqueles elaborados com níveis de substituição de 5\% e 10\% de farinha de trigo por farinha de maçã (Protzek et al., 1998b).

Através dessas pesquisas, pode-se afirmar que além dos produtos a base de maçã comercialmente conhecidos, outros produtos, como bolos, biscoitos e pães poderão ser feitos utilizando como ingrediente o bagaço da maçã.

Esses produtos podem ser destinados aos indivíduos que necessitam de um aporte maior de fibras, e até mesmo para a população em geral, como um meio de prevenir o desenvolvimento de doenças, principalmente as cardiovasculares, através do aumento de fibras na dieta.

\subsection{Consumo de vegetais $\mathrm{x}$ Benefícios à saúde}

Os efeitos do consumo de vegetais, tanto em humanos, como em animais experimentais são amplamente estudados (Lampe, 1999).Vários mecanismos de ação já estão bem esclarecidos por pesquisas científicas realizadas no mundo todo, embora outros muitos mecanismos ainda encontram-se desconhecidos, o que incentiva, cada vez 
mais, a realização de novos estudos.

Oliveira et al. (2003) estudou por 1 ano o consumo de frutas em mulheres, entre 30 e 50 anos, com hipercolesterolemia e sobrepeso $\left(\mathrm{IMC}^{2}>25 \mathrm{Kg} / \mathrm{m}^{2}\right.$ ). Essas foram divididas em três grupos diferentes recebendo, três vezes ao dia, uma dieta com: $300 \mathrm{~g}$ de maçã, 300g de pêra e $60 \mathrm{~g}$ de biscoito de aveia. Durante a pesquisa, a distribuição calórica da dieta foi de 55\% de carboidratos, 15\% de proteína e 30\% de gordura.

Foi concluído, ao final do estudo, que o grupo que consumiu frutas (maçã e pêra) reduziu $1,21 \mathrm{~kg}$ do seu peso enquanto que o grupo que consumiu biscoito de aveia reduziu apenas $0,88 \mathrm{~kg}$. Essa diferença foi significativa, assim como o baixo consumo de calorias. Os autores concluíram nesse estudo que, o consumo de frutas pode reduzir o peso quando aliado a uma dieta balanceada e exercícios físicos (Oliveira et al., 2003).

Observou-se, em pessoas sadias, portadoras de algum fator de risco para o desenvolvimento de doenças cardiovasculares, que o consumo de 6 porções de frutas e outros vegetais por dia durante 5 anos foi significativo na redução do aparecimento dessas doenças, principalmente em casos de infarto. Acredita-se que essa prevenção foi efetiva devido a combinação de micronutrientes e fitoquímicos benéficos para a saúde, presentes em frutas e outros vegetais (Liu et al., 2000).

A importância do consumo de frutas, legumes e verduras baseia-se no fato desses alimentos serem ricos em vitaminas, minerais e compostos ativos, capazes de agir em sinergia e/ou isoladamente, através de vários mecanismos de ação diferentes, entre eles: modulação de detoxificação de enzimas, capazes de provocar alterações no DNA (desoxyribonucleic acid), em proteínas e lipídios; indução de enzimas, capazes de promover a detoxificação de substâncias prejudiciais ao organismo; estimulação do sistema imune; redução da agregação plaquetária; modulação da síntese de colesterol e do metabolismo de hormônios; redução da pressão sanguínea e da capacidade antioxidante, antibacteriana e antiviral (Lampe, 1999).

O alto consumo de frutas, e outros vegetais, como castanhas e grãos integrais, associa-se com uma redução significativa do risco de desenvolver doenças

\footnotetext{
${ }^{2}$ IMC - Índice de massa corpórea.
} 
cardiovasculares. O efeito protetor desses alimentos são provavelmente mediados através dos compostos presentes nesses alimentos, incluindo ácidos graxos mono e poliinsaturados, ácidos graxos ômega 3 , vitaminas antioxidantes, minerais, fitoquímicos, fibras e proteína vegetal (Hu, 2003).

Com o objetivo de verificar a relação entre o consumo de frutas, legumes e verduras e o risco de doenças cardiovasculares Bazzano et al. (2002) conduziram um estudo, durante 4 anos, com cerca de 9000 pessoas, de 25 a 74 anos, que não possuíam doenças cardiovasculares. Foi concluído que o grupo que consumiu 3 porções de frutas e vegetais por dia, quando comparado com o que consumiu apenas uma porção, teve uma redução de 27\% na incidência de acidente vascular cerebral (AVC) não fatal e 42\% fatal, de $24 \%$ nos casos de morte por isquemia cardíaca, de $27 \%$ na incidência de morte por doenças cardiovasculares e de $15 \%$ nos casos de morte por outras causas. O consumo de frutas e vegetais foi considerado, pelos autores, como uma das recomendações dietéticas para prevenir as doenças cardiovasculares. Um outro estudo confirma que o consumo de frutas, legumes e verduras pode associar-se com uma redução do risco de acidente vascular cerebral (Johnsen et al., 2003).

Uma pesquisa nacional em que se estudou a freqüência de consumo de diferentes grupos de alimentos, em relação aos níveis de lipídios no sangue, mostrou que o aumento no consumo de frutas e legumes durante 1 ano proporcionou uma redução nos níveis de LDL-C. Por outro lado, o maior consumo de carnes, leite e ovos favoreceu o aumento do LDL-C. Os autores concluíram que, os hábitos alimentares contribuem para as variações na concentração de colesterol sérico, e que a redução nos riscos cardiovasculares podem ser alcançadas por meio do controle dietético (Fornés et al., 2000).

O CARDIO2000, é um estudo que avaliou a associação entre fatores dietéticos e o risco para o desenvolvimento de doenças cardiovasculares em pacientes, entre 58 e 64 anos, internados após o primeiro infarto. Foi observado que, durante 2 anos, o consumo de 5 porções ou mais de frutas por dia foi significativo em reduzir o risco para doenças cardiovasculares em $72 \%$ dos casos, em comparação aos indivíduos que consumiram menos que 1 porção por dia. Com relação aos legumes o consumo de mais de 3 porções 
por dia diminuiu o risco de doenças cardiovasculares em 70\%, em comparação àqueles que não consumiram legumes. Os autores concluíram que o consumo de frutas e legumes pode significativamente exercer um papel protetor contra doenças cardiovasculares (Panagiotakos et al., 2003).

Atualmente, segundo a DRI (Dietary Reference Intake) a quantidade de frutas recomendada por dia é de 2 a 4 porções, um pouco menor que o observado no CARDIO2000 e com relação aos legumes é recomendada de 3 a 5 porções por dia, concordando com a quantidade de porções por dia estudada no CARDIO2000 (The National Academic, 2003).

Para doenças como as cardiovasculares e o câncer a prevenção é a estratégia mais efetiva que o tratamento quando essas doenças já se instalaram (Liu, R. 2003). Portanto é necessário que as pessoas estejam conscientes da importância da educação nutricional, a fim de aumentar o consumo de tais alimentos. Uma pesquisa constatou que em indivíduos apresentando diabetes, hipertensão ou hipercolesterolemia houve um aumento no consumo de frutas, verduras e legumes indicando uma maior conscientização por parte dessas pessoas, de que esses alimentos são necessários para a boa saúde (Liu et al., 2000).

Segundo Hasler (2002), alimentos como soja, aveia, chá verde, tomate, vegetais crucíferos, produtos lácteos fermentados, pescado, psyllium, alho, entre outros, além de fornecer nutrientes necessários para o aporte calórico, contêm significativas quantidades de compostos bioativos, podendo exercer um papel importante na prevenção de certas doenças.

São muitos os fatores dietéticos que possivelmente promovem efeitos benéficos à saúde Liu, R. (2003) destaca o efeito aditivo proveniente do consumo de frutas, legumes e verduras, no qual o consumo de uma dieta cada vez mais variada, nesses alimentos, proporciona um menor risco de desenvolver doenças, devido a variedade qualitativa e quantitativa de fitoquímicos presentes nos alimentos vegetais. 


\subsection{Fitoquímicos e alimentos com efeito hipocolesterolêmico}

Inúmeros estudos têm mostrado que as frutas contém fitoquímicos capazes de reduzir ou controlar os níveis de colesterol sangüíneo. Dentre os fitoquímicos mais estudados, estão as fibras; minerais; vitaminas, principalmente as vitaminas E, C e A; pigmentos carotenóides tais como o beta-caroteno, licopeno, luteína, etc. e os compostos fenólicos, como por exemplo, as catequinas, antocianidinas, quercetinas, limonóides, campferol, etc. (Colli et al., 2002 ; De Angelis, 2001; Rossi, 2001).

Fitoquímicos são componentes bioativos não nutrientes e estão presentes em todos os vegetais. Essas substâncias têm sido apontadas na prevenção de doenças crônicas. Estima-se que mais de 5000 fitoquímicos foram identificados, mas muitos ainda necessitam ser determinados (Shahidi \& Naczk, 1995).

A vitamina $C$, além de suas funções conhecidas, atua também como agente protetor à peroxidação lipídica, antioxidante e antimutagenico (Costa et al., 2000; Machlin, 1991).

\subsubsection{Fibras}

As fibras alimentares, de acordo com suas características físicas e fisiológicas, podem ser divididas em solúveis e insolúveis. As fibras insolúveis são responsáveis pelo aumento do bolo fecal e pela redução do tempo de trânsito no intestino grosso, tornando a eliminação fecal mais fácil e rápida e diminuindo o risco do aparecimento de hemorróidas, diverticulites e câncer de cólon (Colli et al., 2002).

Quanto às fibras solúveis, vários estudos confirmam que elas agem favoravelmente na redução dos níveis de colesterol sangüíneo. As propriedades das fibras solúveis, devem-se principalmente à sua viscosidade que provoca redução da absorção de lipídeos e de colesterol do intestino delgado (De Angelis, 2001; James et al., 2003).

Além da capacidade quelante das fibras aos ácidos biliares que "carregam" o colesterol exógeno para as fezes, causando uma diminuição da absorção de ácidos biliares pelo fígado, a excreção de ácidos biliares provoca um aumento na conversão de 
colesterol sérico nesses ácidos reduzindo assim o colesterol hepático e sanguíneo (Camire \& Dougherty, 2003; Elhardallou, 1992; Savaiano, 2000).

Outro efeito benéfico produzido pelas fibras, é que quando presentes elas são fermentadas por colônias de bactérias no intestino grosso, produzindo ácidos graxos de cadeia curta, que devem inibir a síntese de colesterol hepático promovendo a utilização do colesterol exógeno (James et al., 2003; Marcil et al., 2002).

Um estudo de metaanálise conduzido por Brown et al. (1999), no qual foram analisados 67 estudos clínicos sobre o efeito da fibra solúvel na redução do colesterol, constatou que na maioria dos estudos (60 a 70\%) foi observada uma redução significativa nos níveis séricos de colesterol total e LDL-C em dietas com altos teores de fibras solúveis.

Dietas com alto teor de fibras, principalmente a fração solúvel são recomendadas para prevenção de doenças cardiovasculares.Bazzano et al. (2003) conduziu um estudo epidemiológico durante 19 anos e observou que, os indivíduos que consumiram uma dieta contendo 5,9 g/dia de fibras solúveis diminuíram em 10\% o risco de desenvolver doenças cardiovasculares em comparação aos que consumiram 0,9 g/dia.

Em relação às atuais recomendações (DRI) de fibras totais, o valor que fornece maior proteção contra doenças cardiovasculares é de 25 a $30 \mathrm{~g}$ de fibra total por dia (The National Academic, 2003), no qual 6 g/dia deveria ser referente às fibras solúveis (Mahan, 1998). No entanto, Leedes \& Hussain (1998) afirmam que é necessário uma dose mínima de $3 \mathrm{~g} /$ dia de fibras solúvel para haver uma diminuição da lipidemia. O efeito das fibras no consumo de produtos alimentícios fortificados na redução do colesterol é muito útil, devido ao alto custo dos tratamentos com drogas redutoras da colesterolemia, além de abranger a população em geral como prevenção.

A fibra solúvel mais divulgada nos alimentos é a pectina, um ácido poligalacturônico encontrado em frutas e outros vegetais, principalmente em maçãs, cenouras e laranjas (Corrêa, 2002). Há vários trabalhos que mostram o efeito da pectina na redução do colesterol plasmático.

González et al. (1998) pesquisaram o efeito da pectina cítrica e da maçã no metabolismo do colesterol por 3 semanas em ratos. Foi observado que a maior redução 
do colesterol hepático foi alcançada ao se utilizar 5\% de pectina tanto da maçã como cítrica (33,8\% e 34\%, respectivamente). Já, com relação ao colesterol total houve uma maior redução na dieta com 2,5\% de pectina da maçã e cítrica (26,5\% e 26\%, respectivamente). Esses valores podem justificar os efeitos benéficos da pectina na redução do colesterol, influenciando então o desenvolvimento de doenças cardiovasculares.

Piedade \& Canniatti-Brazaca (2003), pesquisaram o efeito da ingestão do resíduo do abacaxizeiro na lipidemia em ratos Wistar hipercolesterolêmicos. Os tratamentos foram feitos com diferentes níveis de resíduo do abacaxizeiro e pectina cítrica de alta metoxilação $(10 \%, 15 \%$ e $25 \%)$ aos 15,30 e 45 dias. Foi observado que todos os animais tratados com pectina apresentaram menor ganho de peso em relação aos tratamentos utilizando resíduo. Além disso, todos os parâmetros lipidêmicos avaliados (colesterol total, LDL-C, HDL-C e colesterol hepático) foram mais satisfatórios quando se usou pectina cítrica em comparação com o resíduo do abacaxizeiro.

Outro estudo que avaliou o efeito da pectina nos níveis de colesterol utilizou pectina cítrica comercial de alta e baixa metoxilação e celulose nas concentrações de $5 \%, 10 \%, 15 \%$ e $25 \%$. A pesquisa mostrou que houve redução no ganho de peso com o aumento da quantidade de fibra, e os tratamentos com pectina de alta metoxilação nas concentrações de $10 \%$ e $15 \%$ foram os que apresentaram melhores resultados em relação aos teores de colesterol total, triglicerídeos, LDL-C e HDL-C (Fietz, 1998).

Em vários estudos em que é utilizada a pectina, esta é proveniente de maçãs (Aprikian et al., 2003; González et al., 1998; Grudeva- Popova et al., 1997; Harris et al., 2000) ou de frutas cítricas (Frietz, 1998; Piedade \& Canniatti-Brazaca, 2003). Segundo Dreher (1987) algumas variedades de maçã e os bagaços de laranja são as duas principais fontes comerciais de pectina.

\subsubsection{Compostos fenólicos}

Os compostos fenólicos constituem a maior categoria de fitoquímicos em vegetais (De Angelis, 2001). Os efeitos fisiológicos antioxidantes de alimentos ricos em fenóis, como por exemplo, em frutas, legumes, sucos de frutas, vinho tinto, chás, café e 
chocolate têm sido alvo de muitas pesquisas, a fim de comprovar a correlação entre o consumo desses alimentos e a redução da mortalidade por doenças cardiovasculares (Hertog et al., 1995; Tijburg et al., 1997).

Yokozawa et al. (2002) estudando o efeito do chá verde em ratos, observaram que, houve uma significativa ação antiaterogênica devido ao aumento do HDL sanguíneo.

O efeito do consumo de flavonóides sintéticos também é alvo de estudos sobre o metabolismo lipídico. Uma pesquisa utilizando baicaleína, morina, quercetina, naringenina, naringina e rutina proporcionaram uma redução significativa na lipidemia em ratos da linhagem Wistar com hiperlipidemia (Gomes, 1998).

Pereira (1999) realizou um estudo com ratos Wistar com o objetivo de avaliar os efeitos de flavonóides e corantes sobre os níveis de colesterol. Foram utilizados os flavonóides: campferol, biochanina A, naringina, entre outros, e os corantes naturais: manascus, antocianina, carmim e clorofila. Todas as substâncias testadas tanto isoladamente como em associação, apresentaram redução do colesterol total, mostrando efeitos hipolipidêmicos.

Outros compostos pertencentes ao grupo dos polifenóis são os taninos, que divididem-se em dois grupos: os hidrolisáveis e os condensados (Macheix et al., 2000).

Wilska-Jeszka (1996) observou que existem, em muitas frutas, taninos, principalmente os condensados (proantocianidinas). As proantocianidinas e seus precursores como as catequinas, são compostos bioativos que agem na prevenção de algumas doenças do aparelho circulatório e possuem propriedades antioxidantes.

Liu, J. et al. (2003) verificou uma diminuição da pressão sanguínea em um estudo in vitro utilizando taninos extraídos de ervas chinesas, os autores concluíram que o consumo de alimentos contendo uma certa quantidade de taninos produzem efeitos benéficos.

As leguminosas são consideradas ricas em compostos fenólicos e taninos. Com o objetivo de avaliar o efeito do consumo de feijão em algumas variedades na redução do colesterol sanguíneo em ratos, Rosa (1996) observou que, o consumo, por 28 dias, de $30 \%$ de feijão de cada tipo (preto, vermelho e carioquinha) reduziram em 16,2\%; 11,8\% 
e 11,1\%, respectivamente, os níveis de colesterol total sanguíneo em relação com o controle.

Plantas ricas em taninos são empregadas na medicina tradicional como remédios para o tratamento de diversas moléstias orgânicas, tais como: diarréias, hipertensão arterial, reumatismo, hemorragias, feridas, queimaduras, problemas estomacais, problemas renais e do sistema urinário e processos inflamatórios em geral (Haslam, 1996).

Apesar de existirem fatores antinutricionais atribuídos aos taninos, como por exemplo, inativação de enzimas digestivas e redução na absorção de nutrientes há também propriedades benéficas, agindo como antioxidantes naturais, atividade anticarcinogênica, menor incidência de doenças coronarianas e ação bactericida e fungicida (De Angelis, 2001).

\subsubsection{Minerais}

Os minerais são úteis a uma variedade de funções, tais como co-fatores em reações catalisadas por enzimas, na regulação do balanço ácido-base, no impulso nervoso, atividade muscular e como elementos estruturais do corpo (Bianchi et al., 2000).

São muitos os trabalhos que mencionam os minerais como substâncias benéficas à saúde. Vaskonen (2003) afirma que, um alto consumo de cálcio, magnésio e potássio aliado a um consumo reduzido de sódio relaciona-se com uma ação anti-hipertensiva em humanos. Especialmente o cálcio tem sido benéfico na redução da lipidemia.

Foi observado que, em homens e mulheres, entre 20 e 65 anos, o consumo de cálcio em valores maiores que $1000 \mathrm{mg}$ foi associado com uma redução significativa de 10\% da razão colesterol total:HDL-C em comparação com os indivíduos que consumiram valores menores que 600 mg de cálcio. Segundo os autores, os indivíduos que consomem maiores teores de cálcio possuem um menor risco de sofrer doenças cardiovasculares (Jacqmain et al., 2003).

Segundo Hamilton et al. (2000), uma deficiência de cobre (0,2 mg/Kg de dieta) pode estar relacionada com o desenvolvimento de lesões na artéria aorta, sendo assim, é 
considerado por esses autores um mineral essencial na manutenção do sistema cardiovascular.

Apesar dos efeitos benéficos dos minerais, altos teores de ferro podem levar à peroxidação lipídica pela formação de radicais livres, tornando-se um fator de risco para a aterosclerose (Kiechl et al., 1997). No entanto, outros pesquisadores indicam que, numa dose recomendada, esse mineral pode auxiliar na redução da lesão em artérias (Dabbagh et al. 1997)

Segundo Tsuji et al. (1994), a suplementação com magnésio e potássio tem sido utilizada na prevenção e no tratamento tanto de arritmias quanto de infarto do miocárdio, doenças essas que podem relacionar-se com o processo de aterosclerose. Um estudo em pacientes com infarto agudo do miocárdio sugere uma mortalidade reduzida com o tratamento com magnésio comparando-se com o controle (Orlov et al., 1994).

\subsection{Maçã: seus nutrientes e componentes ativos}

Os efeitos benéficos provenientes do consumo da maçã, principalmente na redução do colesterol, alvo de muitas pesquisas em todo o mundo, são freqüentemente atribuídos aos componentes presentes na maçã, como as fibras, vitamina $\mathrm{C}$ e compostos fenólicos. Esses vão agir em conjunto, exercendo ações positivas para aqueles que consomem a fruta regularmente, seguem um estilo de vida saudável, uma dieta equilibrada e variada principalmente em relação às frutas, legumes e hortaliças.

Wang et al. (1996) estudando a capacidade antioxidante total em frutas, pelo método ORAC (Oxygen Radical Absorbance Capacity), verificaram que a maçã pode ser considerada como uma fruta de poder antioxidante, entre outras, como o morango, ameixa, laranja, uva rosada, kiwi, grapefruit, uva branca, banana, tomate, pêra e melão.

Leontowicz et al. (2001) encontraram no bagaço de maçãs, cerca de 16\% de fibra total, sendo 3\% de fibra solúvel e 13\% de fibra insolúvel, todas em base seca. Em tabelas de composição de alimentos, pode-se observar que os teores de fibras totais variaram, discretamente, de 1,97 g/100g (Philippi, 2001) a 2,2 g/100g (Food and Agriculture Organization - FAO, 2003; Universidade de São Paulo - USP, 2003) em base fresca. 
Outros trabalhos analisaram casca e polpa de maçãs. Leontowicz et al. (2002) encontraram em casca de maçã 2,6 a 3,3 g/100g de fibra total e na polpa apenas 1,1 a 1,6 g/100g de fibra total, ambos na base fresca. Leontowicz et al. (2003), analisando maçãs da variedade Golden Delicious, observaram na polpa e na casca 2,2 g/100g e 2,9 g/100g de fibra total, respectivamente, na base fresca.

Quanto aos fenóis totais em maçã, foram encontrados teores de 0,418 g/100g em base fresca, em maçãs da variedade S'ampion (Leja et al.,2003). No entanto, Vinson et al. (2001) encontraram 0,18 g/100g de fenóis totais em base fresca. E Leontowicz et al. (2003), na variedade Golden Delicious, encontraram, em base fresca, teores de fenóis totais na casca de $0,11 \mathrm{~g} / 100 \mathrm{~g}$ e na polpa de $0,06 \mathrm{~g} / 100 \mathrm{~g}$.

O motivo pelo qual há tantas diferenças no teor de fibras e fenóis entre os estudos pode ser explicado pelas diferenças entre as variedades de maçã, por variações no clima, solo, etc, pela utilização de partes diferentes do frutos, no que diz respeito à casca e à polpa, visto que na casca os teores de fibras e fenóis são maiores.

As maçãs contém uma variedade de compostos fenólicos, os quais são descritos na literatura como substâncias com capacidade antioxidante, muitas vezes atuando no metabolismo de lípides (Tomás-Barberán \& Clifford, 2000). Os polifenóis podem atuar também como inibidor da oxidação da LDL-C e agregação plaquetária, conferindo uma proteção contra o desenvolvimento da aterosclerose (Cook \& Samman, 1996). Segundo Gorinstein et al. (2001), a maçã é parte de uma dieta antiaterogênica devido aos altos teores de fibras e de fenóis totais.

Na população norte americana, foi estimado que o consumo de maçã é responsável por 22\% da ingestão per capita de polifenóis em frutas, ficando atrás apenas da banana com 32\%. Essa porcentagem é provavelmente maior em áreas/locais de venda onde há uma divulgação maior do teor de polifenóis em maçã e seu poder antioxidante benéfico à saúde (Vinson et al., 2001). 


\subsection{Efeitos benéficos no consumo de maçãs na lipidemia}

O uso de ratos como modelo animal, para estudos sobre o colesterol, intensificou-se na década de 50, com o interesse cada vez mais crescente na etiologia da aterosclerose (Rosa, 1996).

Aprikian et al. (2001) observaram que uma dieta com 15\% de maçã, da variedade Gala, oferecida a ratos hipercolesterolêmicos durante 21 dias, reduziu o colesterol total no plasma em 9,3\%, enquanto que a redução do colesterol no fígado e triglicerídeo plasmático não foi significativa. O colesterol excretado, presente nas fezes, foi maior no grupo que consumiu maçã do que no controle, mostrando uma baixa absorção desse.

Leontowicz et al. (2001) observaram o efeito de dietas suplementadas com polpa de beterraba (10\%) e bagaço de maçã (10\%) durante 40 dias, sobre o metabolismo de colesterol em ratos hipercolesterolêmicos da linhagem Wistar. Ao final do experimento, concluiu-se que houve uma redução de $20 \%$ do colesterol total utilizando beterraba e de 18,4\% utilizando-se maçã. Na análise do LDL-C houve uma redução de 32,6\% nos animais com a dieta suplementada com beterraba e 31,2\% na dieta com maçã. Os níveis de triglicerídeos apresentaram uma redução de 17\% na dieta contendo beterraba e de 14,8\% na dieta contendo maçã. Quanto aos níveis de HDL-C não houve alterações significativas entre as dietas, no entanto, para os níveis de colesterol hepático, ambas as

dietas apresentaram menor teor em comparação com o controle, indicando que os vegetais avaliados impediram um aumento do colesterol hepático, seja por inibir a síntese ou por impedir a absorção.

Uma concentração menor de maçã foi utilizada por Bobek et al. (1998), para avaliar o efeito do consumo da maçã em ratos hipercolesterolêmicos. Os autores observaram que, dietas suplementadas com 5\% de maçã, 5\% de tomate e 5\% de uva desidratados, por 70 dias, não diferiram do grupo controle, em relação aos níveis de colesterol total e de triglicerídeos séricos. Entretanto, houve uma redução significativa de $15 \%$, nos níveis de colesterol hepático, no grupo que recebeu tomate e de $11 \%$ no grupo que recebeu maçã. A atividade de enzima HMG CoA redutase, responsável pela síntese do colesterol, foi reduzida em $60 \%$ no grupo que recebeu maçã, $70 \%$ no grupo 
que recebeu uva e 59\% no grupo que recebeu tomate. Quanto ao ganho de peso dos ratos, não houve alteração considerável.

Aprikian et al. (2002) observaram que uma dieta suplementada com 20\% de maçã em ratos hipercolesterolêmicos, durante 21 dias, reduziu em 22\% o nível de colesterol total e 70\% o nível de LDL-C. Para os níveis de colesterol no fígado e no músculo cardíaco a dieta suplementada com maçã não apresentou diferenças comparando-se com o grupo controle. Foi observado, em ratos alimentados com maçã, um aumento de 30\% do teor de ácidos biliares nas fezes. Os autores concluíram que o consumo de maçã em ratos apresenta resultados positivos em relação à lipidemia devido aos componentes ativos presentes na fruta, como as fibras e os fenóis totais.

Outro estudo sobre os efeitos benéficos do consumo de maçã na prevenção de doenças cardiovasculares demonstrou que uma suplementação de $10 \%$ de maçã na dieta de ratos hipercolesterolêmicos, durante 28 dias, promoveu uma significativa redução de 20\% nos níveis de colesterol total, 32,6\% nos níveis de LDL-C e de 17\% nos níveis de triglicerídeos, comparando com o grupo controle (Leontowicz et al., 2002).

Resultados semelhantes foram encontrados por Leontowicz et al. (2003), quando administrou em ratos hipercolesterolêmicos 10\% de casca e 10\% de polpa de maçã descascadas, em diferentes grupos, durante 30 dias. O grupo que apresentou melhor resultado foi o que consumiu $10 \%$ de casca, pois obteve uma redução de 21,6\% nos níveis de colesterol total, 35,3\% de LDL e 18\% de triglicerídeos, em comparação com o controle. Este estudo apresentou melhores resultados do que o estudo de Leontowicz et al. (2002), pois, apenas utilizando a casca, os resultados foram semelhantes ao trabalho em que se utilizou o fruto inteiro, utilizando a mesma porcentagem de maçã e em períodos semelhantes. Provavelmente, isso seja devido a uma concentração, suficientemente benéfica, de compostos ativos presentes na casca, como fibras e fenóis.

Quanto a absorção e a excreção de colesterol há diferenças encontradas na literatura, entre os homens e os animais usados como modelos experimentais. Enquanto alguns animais, como o rato (Frantz et al. 1954) comporta-se de maneira semelhante ao homem (Quintão et al., 1971) quanto à limitação de absorção do colesterol alimentar, 
outros como o coelho, desenvolvem hipercolesterolemia intensa após eficiente absorção do mesmo (Andersen et al., 1982).

Apesar das diferenças conhecidas entre o metabolismo do colesterol em ratos e em humanos, o rato é tido ainda como o modelo experimental mais acessível, devido ao seu tamanho corporal e ao seu uso intenso em várias pesquisas científicas sérias nacionais e internacionais promovendo um melhor conhecimento, ao longo do tempo, do seu comportamento em situações gerais.

Evidências epidemiológicas sugerem que há uma associação entre o consumo de frutas, legumes e verduras, ricos em fitoquímicos, e um baixo risco no desenvolvimento de doenças crônicas. O mecanismo de ação responsável pelos efeitos benéficos têm sido muito estudados através da administração dessas substâncias ou pelo consumo desses alimentos em ratos (Lampe, 1999).

Em um estudo realizado por Pearson et al. (1999), foi observado que o nível de LDL oxidada diminuiu com a inclusão de extrato de maçã. Nesse estudo, foi empregado uma técnica in vitro utilizando sangue humano. A pesquisa concluiu que o consumo tanto de maçãs in natura como do seu suco industrializado pode ser benéfico para a saúde humana, pois a inibição da oxidação do LDL-C pode prevenir o aparecimento da aterosclerose. 


\section{MATERIAL E MÉTODOS}

\subsection{Local do experimento}

Esse estudo foi realizado no Laboratório de Bromatologia e Nutrição Experimental do Departamento de Agroindústria, Alimentos e Nutrição da Escola Superior de Agricultura "Luiz de Queiroz", USP.

\subsection{Matéria prima}

Foram utilizadas maçãs maduras da variedade Gala obtidas no comércio local de Piracicaba. As maçãs foram higienizadas, cortadas em pedaços e colocadas em bandejas para secagem em estufa de circulação de ar forçada, a uma temperatura entre 55 e $60^{\circ} \mathrm{C}$, durante 48 horas. Assim que as maçãs foram cortadas e dispostas nas bandejas, foi distribuído sobre cada bandeja, aproximadamente, $100 \mathrm{ml}$ de uma solução de ácido ascórbico a uma concentração de $1 \%$.

As amostras secas foram moídas em moinho de facas (modelo T345 - marca Tecnal), o material obtido foi conservado em sacos plásticos e mantido sob refrigeração até o momento do uso.

\subsection{Análises químicas da maçã}

As maçãs foram caracterizadas quimicamente com o objetivo de se avaliar sua composição centesimal, o teor de vitamina C, a presença de taninos e compostos fenólicos. Apenas o teor de vitamina C foi determinado com a maçã fresca, as outras determinações foram feitas com a maçã pré-seca, e, principalmente os taninos e compostos fenólicos, foram determinados imediatamente após o processo de secagem, 
para preservar os componentes presentes. Todas as determinações foram feitas em triplicata.

\subsubsection{Composição centesimal da maçã}

Os teores de umidade, cinza, lipídios e proteína foram analisados conforme metodologia oficial da Association Official Analytical Chemists - AOAC (1995). Para obtenção do teor de proteína, multiplicou-se o valor do nitrogênio total, obtido através do método micro kjeldahl, pelo fator 6,25.

O teor de fibras solúveis e insolúveis foram avaliados utilizando metodologia proposta por Asp (1983).

Os minerais fósforo, potássio, cálcio, magnésio, enxofre, sódio, cobre, ferro e zinco foram determinados segundo Sarruge \& Haag (1974).

\subsubsection{Determinação de vitamina $C$}

Para avaliação do conteúdo de vitamina C empregou-se a metodologia de Pregnolatto \& Pregnolatto (1985), utilizando o método de Tillmans.

\subsubsection{Determinação de taninos e compostos fenólicos}

Para a determinação de compostos fenólicos totais utilizou-se a metodologia de Swain \& Hillis (1959). E para a obtenção dos teores de taninos foi utilizada a técnica de Price et al. (1978).

\subsection{Ensaio biológico}

O ensaio biológico teve como objetivo principal testar várias concentrações de maçã Gala sobre parâmetros lipidêmicos e nutricionais de ratos hipercolesterolêmicos.

\subsubsection{Dietas}

Foram preparadas três dietas experimentais com maçã (5\%, 15\% e 25\%) e uma dieta controle, todas elas acrescidas de banha de porco. As dietas foram preparadas conforme Reeves et al. (1993). 
A banha de porco foi utilizada como fonte de colesterol, e para determinar seu teor empregou-se a metodologia de Pregnolatto \& Pregnolatto (1985).

\subsubsection{Preparo das dietas}

As dietas foram elaboradas em lotes variando-se apenas o nível de maçã em detrimento do amido e utilizando a caseína como fonte protéica. A seguir, foram colocadas em sacos plásticos e congeladas a $-18^{\circ} \mathrm{C}$, enquanto não usadas no momento. A Tabela 1 apresenta a composição das 4 dietas avaliadas no experimento.

Tabela 1. Composição das dietas controle e suplementadas com maçã Gala.

\begin{tabular}{|c|c|c|c|c|}
\hline \multirow[t]{2}{*}{ COMPONENTES } & \multicolumn{4}{|c|}{ DIETAS } \\
\hline & Controle & 5\% de maçã & 15\% de maçã & 25\% de maçã \\
\hline Caseína $^{1}$ & $15 \%$ & $15 \%$ & $15 \%$ & $15 \%$ \\
\hline Maçã ${ }^{2}$ & - & $5 \%$ & $15 \%$ & $25 \%$ \\
\hline Mistura mineral $^{3}$ & $3,5 \%$ & $3,5 \%$ & $3,5 \%$ & $3,5 \%$ \\
\hline Mistura vitamínica ${ }^{4}$ & $1 \%$ & $1 \%$ & $1 \%$ & $1 \%$ \\
\hline Óleo de soja ${ }^{5}$ & $3 \%$ & $3 \%$ & $3 \%$ & $3 \%$ \\
\hline Banha de porco $^{6}$ & $7 \%$ & $7 \%$ & $7 \%$ & $7 \%$ \\
\hline Bitartarato de colina $^{7}$ & $0,25 \%$ & $0,25 \%$ & $0,25 \%$ & $0,25 \%$ \\
\hline Sacarose $^{8}$ & $10 \%$ & $10 \%$ & $10 \%$ & $10 \%$ \\
\hline$\alpha-$ cistina $^{9}$ & $0,3 \%$ & $0,3 \%$ & $0,3 \%$ & $0,3 \%$ \\
\hline Tert-butilhidroquinona $^{10}$ & $0,0014 \%$ & $0,0014 \%$ & $0,0014 \%$ & $0,0014 \%$ \\
\hline Amido $^{11}$ & \multicolumn{4}{|c|}{ Para completar $100 \%$} \\
\hline
\end{tabular}

${ }^{1}$ Synth; ${ }^{2}$ Variedade Gala; ${ }^{3}$ Reeves, et al., 1993; ${ }^{4}$ Reeves, et al., 1993; ${ }^{5}$ Lisa ®; ${ }^{6}$ Sadia ${ }^{\circledR} ;{ }^{7}$ Synth; ${ }^{8}$ Vetec; ${ }^{9}$ Synth; ${ }^{10}$ Sigma; ${ }^{11}$ Maizena ${ }^{\circledR}$ 


\subsubsection{Animais}

Foram utilizados ratos machos adultos (Rattus norvegicus var. albinus), da linhagem Wistar, obtidos do biotério da USP em Ribeirão Preto. Os animais permaneceram no local do experimento por 2 semanas em gaiolas coletivas, 6 animais por gaiola, à temperatura controlada $\left(22\right.$ a $\left.23^{\circ} \mathrm{C}\right)$ com ciclo de claro-escuro de 12 horas, recebendo ração comercial Purina ${ }^{\circledR}$ e água ad libitum até adquirirem o peso ideal entre 230 e 250 g, com uma idade média de 3 a 4 meses.

Para obter valores de ratos normais, a fim de ser utilizado como parâmetro de comparação, foram sacrificados 6 animais logo que os mesmos atingiram o peso desejado, recebendo a dieta comercial Purina ${ }^{\circledR}$. Nesse grupo foram dosados os níveis de colesterol total, LDL-C, HDL-C, triglicerídeos e colesterol hepático.

Foram selecionados 54 animais, dos quais 6 ratos, consumiram dieta hipercolesterolêmica (grupo controle inicial - C.I.), permaneceram em gaiolas individuais, em ambiente com temperatura entre $22-23^{\circ} \mathrm{C}$, com um ciclo de claro-escuro de 12 horas, recebendo água ad libitum, esses animais foram sacrificados passada uma semana do início do experimento.

Os 48 animais restantes foram divididos em 4 grupos (controle caseína - C.C., 5\%, 15\% e 25\% de maçã), de 12 animais cada, sendo que, para cada dieta, 6 animais durante 30 dias e outros seis nos 60 dias de experimento. Esses animais também permaneceram em gaiolas individuais, em ambiente com temperatura entre 22 e $23^{\circ} \mathrm{C}$, com um ciclo de claro-escuro de 12 horas. Durante o experimento, que teve duração total de 60 dias, eles receberam água ad libitum, sendo o ganho de peso e o consumo de dieta registrados três vezes por semana.

\subsubsection{Coleta de sangue/fígado e análises bioquímicas}

Os animais do grupo C.I., após jejum de 12 horas, foram sacrificados para coleta de sangue, pela técnica de punção cardíaca, para as análises de colesterol total, HDL-C e triglicerídeo. Na oportunidade, o fígado dos animais também foi coletado para a análise do colesterol hepático. No $30^{\circ}$ dia e no $60^{\circ}$ dia de ensaio, os animais foram igualmente sacrificados sendo realizadas as mesmas análises bioquímicas. 
O sangue foi coletado com anti-coagulante EDTA e a seguir foi centrifugado a 200rpm/10minutos, para a separação das frações soro e plasma. No soro foram dosados níveis de colesterol total, HDL-C e triglicerídeos através do kit da indústria química Wiener Lab e os cálculos foram feitos de acordo com a indicação do mesmo. Os teores de LDL-C foram identificados pela fórmula 1, segundo Friedewald et al. (1972), na qual:

$$
L D L=\text { Colesterol total }-H D L-\left(\frac{\text { Triglicerídeo }}{5}\right)
$$

No final de cada período, o fígado dos animais foi retirado e então utilizado para a determinação do colesterol total no fígado através do método proposto por Haug \& Hostmark (1987). O fígado foi triturado e homogeneizado retirando-se 0,5g para pesagem. Em seguida foi colocado em tubo de centrífuga, adicionando-se então $5 \mathrm{ml}$ de isopropanol, após o qual foi tampado e deixado por dois dias a $4^{\circ} \mathrm{C}$. Posteriomente, a amostra foi centrifugada por 10 minutos a 1000rpm, e, a partir do sobrenadante foi feita a análise do colesterol total, seguindo a mesma metodologia descrita anteriormente.

\subsubsection{Coleta de fezes e análise}

Durante todo o período experimental, três vezes por semana, as fezes dos animais dos grupos C.I., C.C., 5\%, 15\% e 25\% de maçã, em ambos os tempos, foram coletadas em sacos plásticos individuais para cada rato, devidamente identificados e armazenados em refrigerador. No final de todo o experimento, as fezes foram secas em estufa a $105^{\circ} \mathrm{C}$ por 72 horas, moídas em moinho de facas e congeladas para posterior análise. A determinação de colesterol foi feita conforme a análise realizada nos fígados.

\subsubsection{Análise estatística}

O programa estatístico empregado foi o SANEST (sistema de análise estatística), desenvolvido por Zonta \& Machado (s.d.), no qual foi aplicado o teste F para análise de 
variância e o teste de Tukey, com o objetivo de identificar diferenças estatísticas entre as médias. Foi estabelecido $\mathrm{p} \leq 0,05$ como nível de significância. 


\section{RESULTADOS E DISCUSSÃO}

\subsection{Análise química do colesterol alimentar}

O teor de colesterol encontrado na banha de porco, no presente estudo, foi de 206 $\mathrm{mg} / 100 \mathrm{~g} \pm 1,2$. Esse resultado mostrou-se muito semelhantes ao teor encontrado por Franco (1992), encontrando uma quantidade de $243 \mathrm{mg} / 100 \mathrm{~g}$ de colesterol na banha de porco.

\subsection{Análises químicas da maçã}

\subsubsection{Composição centesimal}

Após as maçãs serem submetidas à secagem em estufa foi obtido, na farinha de maçã, um rendimento de 83,22\% em relação à maçã fresca.

O teor de umidade médio encontrado foi de $84,31 \mathrm{mg} / 100 \mathrm{~g} \pm 0,1$. Esse resultado aproxima-se do valor encontrado por FAO (2003) e United States Department of Agriculture - USDA (2003) que, observaram em maçãs Gala, respectivamente, 85,20 g/100g e 85,56 g/100g de umidade.

Os resultados da composição centesimal para proteína, lipídios, cinza, fibras solúveis, fibras insolúveis, fibra total e carboidratos disponíveis, na base seca e fresca, estão representados na Tabela 2. 
Tabela 2. Composição centesimal da maçã variedade Gala.

\begin{tabular}{ccc}
\hline Componentes * & g/100g (seca) & g/100g (fresca) \\
\hline Proteína & $3,61 \pm 0,1$ & $0,57 \pm 0,01$ \\
Lipídios & $1,55 \pm 0,1$ & $0,24 \pm 0,01$ \\
Cinza & $1,53 \pm 0,1$ & $0,24 \pm 0,01$ \\
Fibra solúvel & $10,03 \pm 1,1$ & $1,57 \pm 0,20$ \\
Fibra insolúvel & $2,37 \pm 1,1$ & $0,37 \pm 0,20$ \\
Fibra total & 12,40 & 1,94 \\
Carboidratos disponíveis ** & 80,91 & 12,70 \\
\hline
\end{tabular}

* Média de três repetições

** Por diferença

Em base seca, comparando-se teores de proteína (1,36 g/100g) e lipídios (0,60 g/100g) provenientes da tabela de composição de alimentos USDA (2003), os valores do presente estudo apresentam-se altos, entretanto, concordaram com quantidades de cinza (1,62 g/100g) e de fibras totais (12,78 g/100g). Em maçãs secas, observa-se, quanto ao teor de glicídios, que o teor analisado é maior do que o apresentado por Franco (1992) (40,88 g/100g), no entanto, o valor de lipídios (1,94 g/100g) assemelhou-se à presente pesquisa.

Em várias tabelas de composição de alimentos, expressando os teores em base fresca, os valores de proteína variaram de 0,30 g/100g (Pinheiro, 1993; USP, 2003) a 0,34 g/100g (Franco, 1992) e podem ser considerados um pouco baixos em comparação ao teor de proteína analisado. Com relação aos lipídios, os resultados da presente pesquisa são considerados semelhantes à literatura pesquisada, pois foram encontrados, em maçãs na base fresca, uma quantidade de 0,30 g/100g (Pinheiro, 1993) e de 0,36g/100g (Philippi, 2001).

USP (2003) e FAO (2003) encontraram em maçãs frescas aproximadamente 0,2 g/100g de cinza e na variedade Gala 2,2 g/100g de fibras totais, sendo ambos os 
resultados semelhante à análise feita, discordando apenas no fato de que, em USP (2003), o teor de fibra insolúvel (1,50 g/100g) é maior que o de fibra solúvel (0,7 g/100g). Tal fato também foi observado em Leontowicz et al. (2001) no qual, encontrou, em base seca, uma porcentagem de fibra insolúvel (13,0 g/100g) maior do que a solúvel (3,0 g/100g).

No entanto, as melhores fontes de fibras solúveis são aveia, pêssego, mamão, albeno (parte branca da laranja) e maçã (Corrêa, 2002). Concordando com os resultados analisados nesta dissertação, no qual a maçã possui um teor maior de fibra solúvel do que de insolúvel, o que representa uma grande vantagem na prevenção de doenças cardiovasculares, devido a seus efeitos fisiológicos benéficos com relação a redução do colesterol sanguíneo.

Outros trabalhos que também se aproximaram da presente análise da maçã Gala, com relação às fibras, foi o de Mendez et al. (2001) mostrando 2,13 g/100g de fibra total em maçãs na base fresca, Gheyas et al. (1997) analisando maçãs da variedade Gala, encontrou 2,12 g/100g em base fresca e Philippi (2001), sendo o trabalho que mais se assemelhou à presente dissertação, identificou 1,97 g/100g em base fresca.

De acordo com as novas recomendações (DRI) de consumo de fibras totais (25 a $30 \mathrm{~g}$ por dia) o consumo de uma unidade de maçã (200g) fornece aproximadamente $14,5 \%$ das recomendações.

\subsubsection{Minerais}

A Tabela 3 apresenta os teores dos seguintes minerais: fósforo, cálcio, potássio, magnésio, enxofre, sódio, cobre, ferro e zinco da maçã variedade Gala. 
Tabela 3. Teor de minerais da maçã variedade Gala.

\begin{tabular}{ccc}
\hline Componentes * & mg/100g (seca) & mg/100g (fresca) \\
\hline Fósforo & $107,66 \pm 1,30$ & $16,89 \pm 0,200$ \\
Cálcio & $26,91 \pm 5,30$ & $4,22 \pm 0,800$ \\
Potássio & $988,35 \pm 4,20$ & $158,93 \pm 6,800$ \\
Magnésio & $33,37 \pm 2,80$ & $5,24 \pm 0,400$ \\
Enxofre & $33,37 \pm 2,00$ & $5,24 \pm 0,300$ \\
Sódio & $247,62 \pm 1,00$ & $38,84 \pm 0,010$ \\
Cobre & $0,57 \pm 0,04$ & $0,09 \pm 0,006$ \\
Ferro & $2,60 \pm 0,50$ & $0,41 \pm 0,070$ \\
Zinco & $0,25 \pm 0,04$ & $0,04 \pm 0,010$ \\
\hline
\end{tabular}

* Média de três repetições

Consta na literatura, os efeitos benéficos de uma suplementação com minerais, no controle do desenvolvimento de doenças cardiovasculares, principalmente no que diz respeito ao cálcio, magnésio, potássio e cobre. A maçã, no entanto, não representa um alimento fonte desses minerais, mas essa fruta pode auxiliar a atingir as recomendações principalmente de microminerais, que entre os minerais analisados são: ferro, cobre e zinco.

De acordo com as novas recomendações para homens adultos, entre 19 e 30 anos, de ferro (8 mg/dia), cobre (900 $\mu \mathrm{g} /$ dia) e zinco (11 mg/dia) alcança; segundo os teores de minerais do presente estudo, 10,2\%, 20\% e 0,7\% das recomendações de ferro, cobre e zinco, respectivamente, considerando o consumo de uma maçã (200g) por dia (The National Academies, 2003).

Os fatores que interferem no teor de minerais em vegetais, promovendo uma diferença entre os resultados dos trabalhos apresentados são muitos, como por exemplo, a variedade, o estado de maturação, o tipo e as condições do solo, a fertilização, a irrigação e a temperatura (Tahvonen, 1993). 
Observou-se que o teor de fósforo, encontrado na presente análise, apresentou um valor baixo se comparados com a literatura, em base fresca, como em Philippi (2001) encontrando 7,0 mg/100g e Franco (1992) verificando 6,0 mg/100g.

Gorinstein et al. (2001), analisando maçãs liofilizadas, aproximou-se dos resultados com relação ao teor de cálcio e magnésio, encontrando 4,3 mg/100g e 5,02 $\mathrm{mg} / 100 \mathrm{~g}$ ambos em base fresca, respectivamente.

Philippi (2001) encontrou resultados um pouco abaixo dos que estão sendo apresentados na presente pesquisa com relação ao zinco $(0,02 \mathrm{mg} / 100 \mathrm{~g})$ e ao cobre $(0,04$ $\mathrm{mg} / 100 \mathrm{~g}$ ) ambos expressados em base fresca.

O teor de ferro em maçãs, determinado na presente análise, concorda com os valores apresentados por Pinheiro et al. (1993), o qual encontrou 0,4 mg/100g em base fresca, no entanto em trabalhos como os de Elkins et al. (1996); Gorinstein et al. (2001) e Philippi (2001) foram encontrados valores menores e em Franco (1992) e Tahvonen (1993) quantidades maiores de ferro, comparando-se com a presente pesquisa.

Joshi \& Sandhu (1996), encontraram, em maçãs, valores bem próximos em relação à análise de potássio $(989,0$ mg/100g) e um pouco baixo na análise de sódio (208,0 mg/100g), ambos em base seca.

\subsubsection{Vitamina C}

O teor de vitamina C encontrado no presente estudo foi de 25,0 mg/100g $\pm 2,5$ em base fresca.

Esse teor de vitamina C, encontrado no presente estudo, é semelhante aos valores quantificados por outros pesquisadores. Combs (1998) encontrou uma variação de 10 a 30 mg/100g em maçãs na base fresca. Miller et al. (1995) também encontraram, em suco de maçã, $30 \mathrm{mg} / 100 \mathrm{ml}$, valor próximo ao obtido neste estudo. Segundo as novas recomendações uma maçã (200g) fornece, aproximadamente, 55\% das recomendações de vitamina C (90 mg) para homens adultos na faixa etária entre 19 e 30 anos (The National Academies, 2003).

Todavia, em outras referências, foram encontrados valores bem abaixo variando de 5,7 mg/100g (Philippi, 2001) a 8 mg/100g (Franco, 1992). Essa variação depende de 
fatores como a variedade da fruta, o processamento, as condições do solo, o clima, as condições e o tempo de armazenamento, entre outros (Davies et al., 1991).

\subsubsection{Compostos fenólicos}

Com relação aos compostos fenólicos, no presente trabalho, foram encontrados os valores de 2,43 g/100g $\pm 0,01$ em base seca e 0,38 g /100g $\pm 0,0004$ em base fresca de maçã da variedade Gala.

Vinson et al. (2001) encontraram em maçãs $0,18 \mathrm{~g} / 100 \mathrm{~g}$ em base fresca de compostos fenólicos, ou seja, praticamente a metade do encontrado nesse estudo. No entanto, em um estudo realizado na Polônia, em maçãs da variedade S'ampion o teor de compostos fenólicos foi de 0,418 g/100g em base fresca, sendo então, semelhantes ao encontrado no presente estudo (Leja et al., 2003), apesar da variedade da maçã ser diferente.

Os compostos fenólicos agem como substrato para certas enzimas, como as polifenoloxidases e peroxidases, que são responsáveis pelo escurecimento de frutas, na presença de oxigênio, alterando as características sensoriais e antioxidantes da mesma. Apesar disso, os produtos dessa reação podem reagir com agentes redutores, como o ácido ascórbico, revertendo essa reação (Macheix et al., 2000; Robards et al., 1999).

O ácido ascórbico isolado ou em conjunto pode ser efetivo como agente inibidor da oxidação enzimática (Almeida, 1991; Mendes et al., 1999). Na presente dissertação também foi utilizado ácido ascórbico com o propósito de preservar os compostos fenólicos presentes.

\subsubsection{Taninos}

Quanto ao teor de taninos foi encontrado na presente pesquisa 1,01 g/100g $\pm 0,01$ na base seca e 0,16 g/100g $\pm 0,0002$ na base fresca.

Segundo Wilska-Jeszka (1996), frutas como maçãs e uvas possuem altos teores de taninos, principalmente os condensados, sendo que esse teor pode variar de 3 a 9 g/100g. 
Esses compostos são importantes em muitas frutas influenciando as características sensoriais de cada fruta e de seus produtos. Por outro lado, os taninos condensados (proantocianidinas), e seus precursores como a catequina, são compostos biologicamente ativos agindo na prevenção de doenças, mais especificamente em doenças cardiovasculares e inativando possíveis radicais livres presentes no organismo.

\subsection{Ensaio biológico}

\subsubsection{Consumo alimentar e ganho de peso}

Os valores médios do consumo de dieta (g) e ganho de peso (g) nos animais que permaneceram do começo ao final dos 30 e 60 dias estão dispostos na Tabela 4.

Tabela 4. Consumo de dieta (g) e ganho de peso (g) médios dos animais do tempo 30 e 60 dias.

\begin{tabular}{|c|c|c|c|c|}
\hline \multirow[t]{2}{*}{ Dietas } & \multicolumn{2}{|c|}{ Tempo 30} & \multicolumn{2}{|c|}{ Tempo 60} \\
\hline & $\begin{array}{c}\text { Ganho } \\
\text { de peso }(\mathrm{g})\end{array}$ & $\begin{array}{c}\text { Consumo } \\
\text { de dieta (g) }\end{array}$ & $\begin{array}{c}\text { Ganho } \\
\text { de peso (g) }\end{array}$ & $\begin{array}{l}\text { Consumo } \\
\text { de dieta (g) }\end{array}$ \\
\hline Controle $^{1}$ & $97,1^{2} \pm 2,0^{\text {a3 }}$ & $459,8 \pm 6,8^{\mathrm{a}}$ & $216,8 \pm 13,8^{\mathrm{a}}$ & $922,8 \pm 21,9^{a}$ \\
\hline 5\% de maçã & $96,2 \pm 2,0^{a}$ & $458,6 \pm 4,6^{\mathrm{a}}$ & $210,9 \pm 9,8^{a}$ & $918,4 \pm 17,0^{a}$ \\
\hline 15\% de maçã & $95,7 \pm 2,4^{\mathrm{a}}$ & $457,6 \pm 8,0^{\mathrm{a}}$ & $209,8 \pm 7,8^{a}$ & $910,0 \pm 19,9^{\mathrm{a}}$ \\
\hline 25\% de maçã & $95,4 \pm 1,5^{\mathrm{a}}$ & $456,2 \pm 9,1^{a}$ & $209,0 \pm 1,4^{\mathrm{a}}$ & $904,5 \pm 28,4^{a}$ \\
\hline \multicolumn{5}{|c|}{${ }^{1}$ Sem adição de fibra } \\
\hline${ }^{2}$ Média \pm Desvi & padrão de seis a & mais por tratam & & \\
\hline
\end{tabular}

Pelos resultados apresentados na Tabela 4, pode-se observar que não houve diferenças significativas para o consumo das dietas e ganho de peso entre os 
tratamentos, em ambos os tempos. Entretanto, de maneira geral, os animais do tempo 30 e 60, apresentaram, embora não significativos, uma redução no ganho de peso e no consumo de dieta, com o aumento das concentrações de maçã. Esse aumento associa-se com um teor maior de fibras, principalmente a fração solúvel, e de componentes antioxidantes nas dietas.

As fibras solúveis desenvolvem uma alta viscosidade, que é freqüentemente associada com os efeitos da fibra na diminuição do esvaziamento gástrico, promovendo a sensação de saciedade (Marlett et al., 2002; Plaami, 1997). Provavelmente reduzindo o consumo e conseqüentemente o ganho de peso. Isso pode justificar a redução do consumo de dieta, na presente pesquisa, com o aumento do fornecimento de fibras solúveis o que, pode ter como conseqüência a diminuição do ganho de peso.

Outro fato que pode justificar o menor ganho de peso, aliado às fibras solúveis, pode ser atribuído a uma redução da absorção de nutrientes, inclusive de lipídios, devido a aceleração no trânsito intestinal (James et al., 2003).

Aprikian et al. (2002), que trabalhou com animais com um peso inicial de $150 \mathrm{~g}$ alimentados com uma dieta contendo 20\% de maçã por 21 dias, observaram uma redução de 1,2\% no ganho de peso e um aumento de 0,4\% no consumo alimentar, os resultados foram próximos ao observado na presente análise, apenas quanto a porcentagem de redução no ganho de peso (1,8\%), no grupo que recebeu 25\% de maçã por 30 dias, mas quanto ao consumo alimentar não houve concordância.

Os resultados encontrados por Aprikian et al. (2001) em ratos com 150g, alimentados durante 21 dias com 15\% de maçã, apresentaram uma redução no ganho de peso de 2,9\% e um aumento no consumo alimentar de 2,1\% em comparação ao controle. Esses resultados discordaram dos resultados do presente estudo , pois foi observado no grupo que consumiu a dieta com $15 \%$ de maçã uma redução no consumo alimentar de $0,5 \%$ e no ganho de peso de $1,4 \%$.

A diferença entre os estudos podem ser explicadas devido ao peso inicial dos animais que foram utilizados no experimento, no qual, no presente estudo o peso inicial dos animais foi de 230 a 250g, sendo o peso ideal para se considerar animais adultos. 
No estudo conduzido por Bobek et al. (1998), utilizando ratos com um peso inicial de $60 \mathrm{~g}$, foi observada uma redução de 3,4\% no ganho de peso, em relação ao controle, em ratos consumindo uma dieta com 5\% de maçã durante 70 dias. Esse resultado assemelha-se com os do presente estudo, apesar do peso inicial dos animais, no qual foi encontrado uma redução de 2,7\% em comparação ao controle nos animais que consumiram 5\% de maçã durante 60 dias.

Na Figura 1 pode-se observar os resultados do tempo 30 divididos em quinzenas.

a)

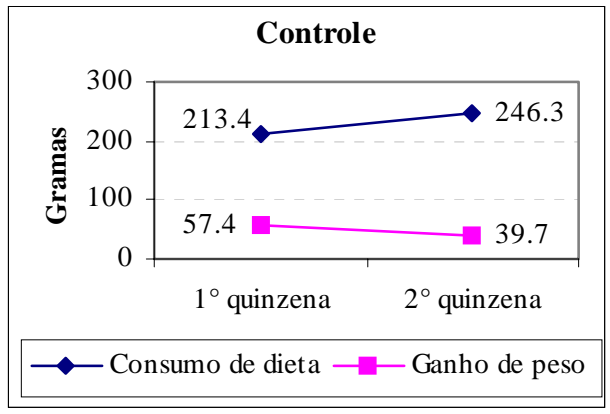

b)

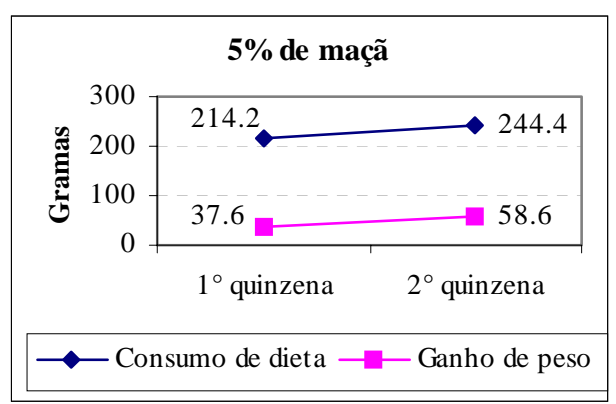

c)

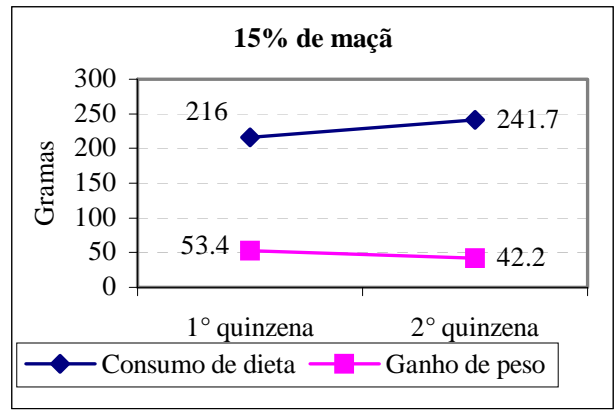

d)

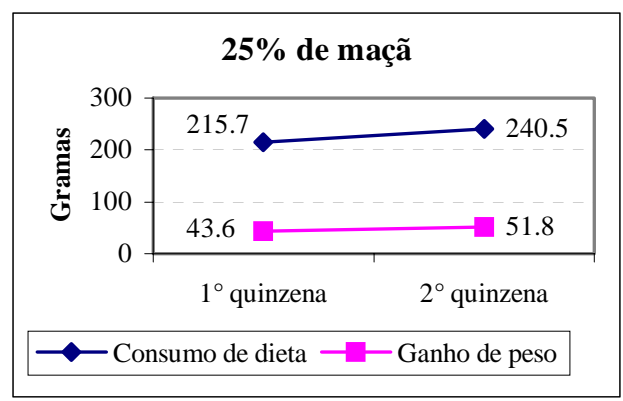

Figura 1 - Consumo de dieta(g) e ganho de peso(g) em quinzenas dos grupos controle (a), 5\% de maçã (b), 15\% de maçã (c) e 25\% de maçã (d) no tempo 30.

Pode-se observar na Figura 1a que o grupo controle apresentou, na primeira quinzena, um maior ganho de peso, em relação às outras dietas experimentais, apesar do menor consumo alimentar. Isso se deve, provavelmente, ao alto teor de gorduras na dieta controle. No entanto, nesse mesmo grupo, na segundo quinzena, o ganho de peso foi baixo, mesmo com um consumo de dieta alto, quanto a isso pode-se supor que, como esse grupo recebeu uma dieta com alto teor de colesterol, provavelmente, ocorreu a 
inibição da síntese, favorecendo o aumento na velocidade de degradação do colesterol e a inibição da sua síntese, favorecendo o aumento na velocidade de degradação do colesterol e da gordura armazenados, em sais biliares, o que foi observado no estudo de Maranhão (1981), observando que quanto maiores os valores de absorção de colesterol, menores os de síntese, inclusive hepática. Pode-se supor que essa depleção impediu que houvesse altas concentrações de gordura no tecido adiposo, o que provavelmente interferiu na redução do ganho de peso na segundo quinzena.

Na dieta contendo 5\% de maçã (Figura 1b), pode-se observar o aumento do consumo de dieta e do ganho de peso entre as quinzenas. Supõem-se que a concentração de maçã presente não foi significativa para alterar o ganho de peso. Já, na dieta com 15\% de maçã (Figura 1c), observa-se um aumento no consumo de dieta acompanhado a uma diminuição do ganho de peso, entre as quinzenas. Provavelmente os compostos presentes na maçã (fibras solúveis) agiram de modo a impedir a absorção de gordura.

Apesar da dieta com 25\% de maçã (Figura 1d) apresentar uma concentração maior de fibras do que as outras dietas experimentais, é alto também o teor de açúcares, como a frutose. Esse carboidrato simples já foi comprovado em aumentar os níveis de triglicerídeos em ratos (Dai \& McNeil, 1992), o que, possivelmente, promove uma maior disponibilidade de ácidos graxos no tecido adiposo devido a ação da enzima lipase lipoprotéica (Martinez, 1997), aumentando assim o ganho de peso na segunda quinzena.

Na Figura 2 pode ser observado os valores de consumo de dieta e ganho de peso nos animais do tempo 60 divididos em quatro quinzenas. 
a)

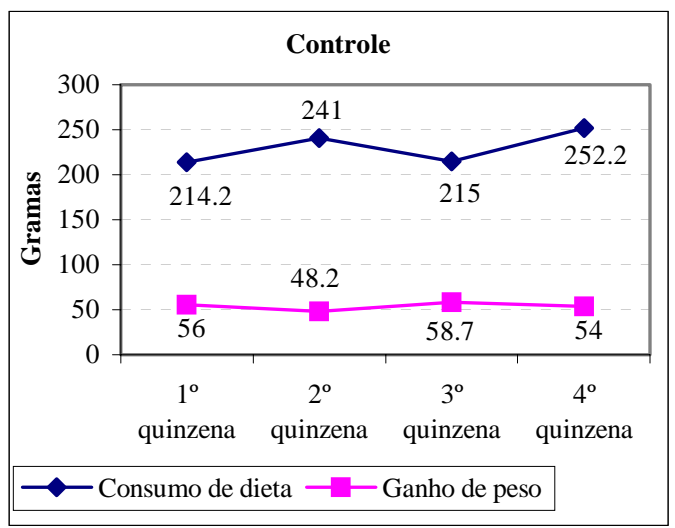

b)

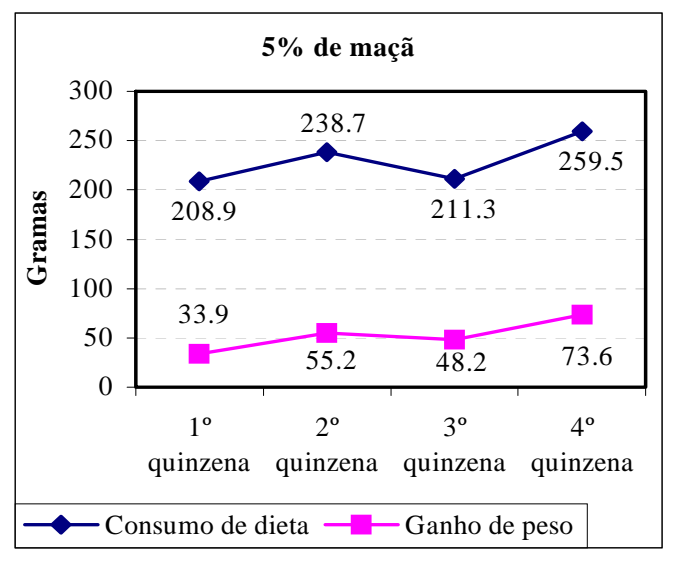

c)

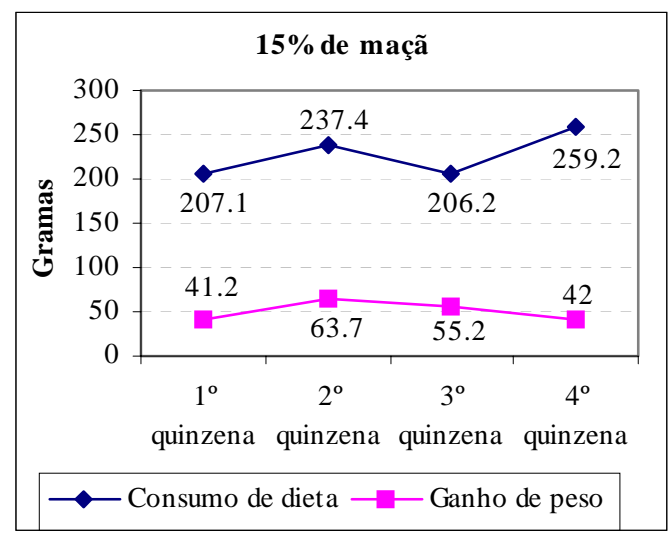

d)

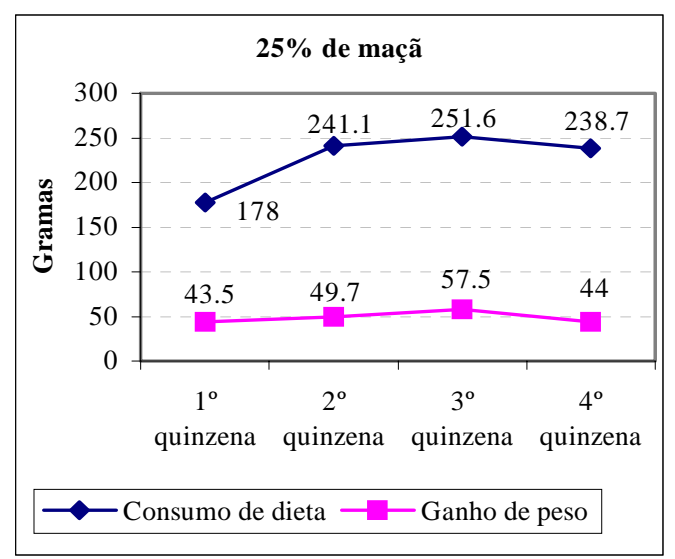

Figura 2 - Consumo de dieta (g) e ganho de peso (g) .em quinzenas dos grupos controle (a), 5\% de maçã (b), 15\% de maçã (c) e $25 \%$ de maçã (d) no tempo 60.

Os resultados para o grupo controle (Figura 2a), no consumo de dieta e ganho de peso, no tempo 60, mostraram-se semelhantes ao observado no tempo 30 , discutido anteriormente, pois pode-se notar que conforme o aumento no consumo da dieta há uma redução no ganho de peso e vice-versa.

Pode-se observar que na dieta com 5\% de maçã (Figura 2b), o comportamento dos animais, quanto ao consumo de dieta e ao ganho de peso foram diretamente proporcionais, indicando que nessa dieta a concentração de fibras não foi suficiente para promover a manutenção do peso corporal como ocorreu para o tratamento com 25\% de maçã (Figura 2d), pois observa-se nessa dieta que um aumento de 35,4\% do consumo da 
primeira para a segunda quinzena não refletiu proporcionalmente no ganho de peso ao longo das quinzenas, permanecendo com valores constantes.

A dieta com 15\% de maçã (Figura 2c), apenas mostrou-se efetiva na redução do ganho de peso a partir da segunda metade do ensaio biológico.

\subsubsection{Análises bioquímicas}

\subsubsection{Colesterol Total}

Na Tabela 5 pode-se observar o efeito das dietas experimentais nos níveis séricos de colesterol total aos 30 e 60 dias de tratamento.

Tabela 5. Concentração plasmática de colesterol total aos 30 e 60. dias em animais .que receberam os tratamentos C.C. (controle caseína), 5\% de maçã, 15\% de maçã e $25 \%$ de maçã.

\begin{tabular}{ccc}
\hline Tratamentos & Colesterol Total $(\mathrm{mg} / \mathrm{dL})$ & Colesterol Total (mg/dL) \\
& 30 dias & 60 dias \\
\hline C.C. $^{1}$ & $92,17^{2} \pm 1,6^{\mathrm{b} 3}$ & $93,61 \pm 1,2^{\mathrm{a}}$ \\
5\% de maçã & $91,46 \pm 1,2^{\mathrm{b}}$ & $92,75 \pm 1,4^{\mathrm{ab}}$ \\
15\% de maçã & $74,40 \pm 0,9^{\mathrm{c}}$ & $91,61 \pm 1,0^{\mathrm{bc}}$ \\
25\% de maçã & $73,04 \pm 0,2^{\mathrm{c}}$ & $90,79 \pm 1,2^{\mathrm{c}}$ \\
\hline
\end{tabular}

${ }^{1}$ Sem adição de fibra

${ }^{2}$ Média \pm Desvio padrão de seis animais por tratamento

${ }^{3}$ Médias com letra(s) diferente(s) na vertical diferem estatisticamente ao nível de significância de $\mathrm{p} \leq 0,05$

O grupo controle inicial (C.I.), ou seja, os animais que permaneceram por 1 semana somente com dieta hipercolesterolêmica, mostrou valores de colesterol de 93,34 
$\mathrm{mg} / \mathrm{dL} \pm$ 0,9 não apresentando diferenças significativas com o grupo controle caseína do tempo 30 e 60, animais que também consumiram dieta hipercolesterolêmica.

Comparando com o valor de colesterol para ratos normais (65,26 mg/dL), esses resultados mostram que o aumento do colesterol total plasmático ocorre a partir de uma dieta rica em gorduras independente do tempo de consumo (1 semana, 30 ou 60 dias).

No estudo de Moundras et al. (1997) o nível de colesterol plasmático, encontrado em ratos normais, foi de $64,1 \mathrm{mg} / \mathrm{dL}$, esse valor apresenta-se muito próximo ao teor encontrado na presente pesquisa.

A dieta com 5\% de maçã, em ambos os tempos, não apresentou diferenças significativas com o controle caseína, indicando que a concentração de 5\% de maçã não foi suficiente para reduzir o colesterol sérico. Nas dietas com 15\% e 25\% de maçã, no tempo 30, proporcionaram uma redução significativa $(\mathrm{p} \leq 0,05)$ nos níveis de colesterol total em relação ao controle, não havendo, diferenças entre ambas.

Observando os resultados da Tabela 5, pode-se notar que os animais que receberam a dieta contendo 15\% de maçã tiveram uma redução significativa de 19,3\% em relação ao controle, enquanto que aqueles que receberam $25 \%$ de maçã, apresentaram uma redução de $20,7 \%$ aos 30 dias de experimento. Pode-se observar na Figura 3 que os valores de colesterol total sérico nos animais que receberam 15\% e 25\% de maçã por 30 dias quase alcançaram os valores para ratos normais (65,26 mg/dL).

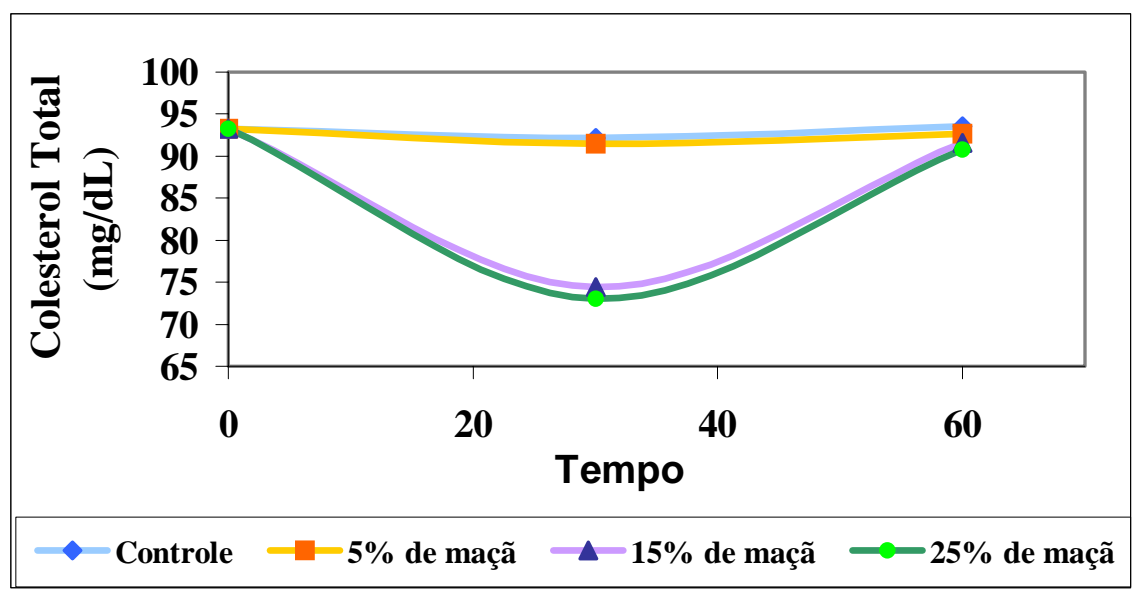

Figura 3 - Níveis séricos de colesterol total (mg/dL) em ratos machos Wistar durante os 60 dias de ensaio biológico. 
Pode-se então propor que, a melhor dieta para promover redução significativa de colesterol total, durante 30 dias, é a de 15\% de maçã, sendo considerada suficiente para produzir alterações benéficas.

No estudo de Leontowicz et al. (2002) fornecendo aos ratos hipercolesterolêmicos uma dieta contendo $10 \%$ de maçã durante 28 dias, foi possível observar uma redução significativa de $19 \%$ no colesterol total em comparação com o controle. Esses valores estão de acordo com a porcentagem de diminuição, encontrada na presente pesquisa, aos 15\% de maçã (19,3\%). Outro estudo, que aproximou-se dos resultados encontrados na mesma dieta, foi realizado por Leontowicz et al. (2001) administrando uma dieta com 10\% de maçã por 40 dias em ratos hipercolesterolêmicos, observando uma redução significativa de $18 \%$ no colesterol total.

No entanto, em um estudo realizado por Aprikian et al. (2001) os resultados discordaram da presente pesquisa, no qual nos animais alimentados com 15\% de maçã durante 21 dias foi observada uma redução de apenas 9,7\%.

Aprikian et al. (2002), utilizando uma dieta hipercolesterolêmica contendo 20\% de maçã, obteve uma redução de $21,7 \%$ em comparação com o controle. Esses resultados foram semelhantes ao encontrado no presente estudo na dieta com $25 \%$ de maçã aos 30 dias (redução de 20,7\%).

Vários estudos têm mostrado que as fibras solúveis agem favoravelmente na redução dos níveis de colesterol sangüíneo.

Camire \& Dougherty (2003) e Savaiano (2000) atribuem a redução do colesterol plasmático à capacidade das fibras solúveis em ligar-se irreversivelmente aos ácidos biliares "carregando-os" para as fezes, impedindo a sua absorção pelo fígado, fazendo com que esse órgão sintetize novamente sais biliares utilizando o colesterol sanguíneo.

Outro efeito fisiológico importante, promovido pelas fibras, é a formação de uma estrutura viscosa que reduz a absorção de alguns compostos, inclusive de lipídeos e de colesterol no intestino delgado (De Angelis 2001; Savaiano 2000).

A fermentação das fibras por colônias de bactérias presentes no intestino grosso, também pode influenciar na colesterolemia, através da produção de ácidos graxos de cadeia curta. Esses componentes podem influenciar a absorção de lipídeos, o 
metabolismo de lipoproteínas no fígado e a síntese de colesterol pelo fígado promovendo, possivelmente, a utilização do colesterol presente no sangue (Marcil et al. 2002; Corrêa 2002).

Apesar dos mecanismos hipocolesterolemiantes das fibras serem amplamente conhecidos e divulgados, no presente trabalho, não pode-se atribuir esses efeitos somente às fibras, já que a maçã possui outros compostos bioativos agindo tanto diretamente na redução do colesterol total e frações como na capacidade antioxidante impedindo a formação da LDL-C oxidada, sendo essa uma importante precursora da aterosclerose. O teor de taninos e fenóis totais, presentes na maçã, também são responsáveis pelos efeitos benéficos na redução do colesterol total e frações.

Quando avaliamos os resultados no tempo 60, verifica-se que os níveis sanguíneos de colesterol total nos animais alimentados com 5\% de maçã foram significativamente semelhantes aos do controle. Já, os valores de colesterol total nos grupos que receberam dietas com $15 \%$ e $25 \%$ de maçã não foram significativamente semelhantes ao controle, mas pode-se observar na Figura 3, que alcançou valores bem próximos.

Um fator que pode ter contribuído para o aumento do colesterol total no tempo 60 é a alta concentração de frutose presentes em maçãs. Dai et al. (1994), utilizando uma alta dose de frutose, em ratos diabéticos e não diabéticos, durante um período de 90 dias observaram alterações no sistema cardiovascular em ratos, principalmente na pressão sanguínea e no metabolismo da glicose e lipidemia.

Diante desses resultados confirma-se a necessidade de um programa de incentivo ao consumo de uma dieta rica em frutas aliada a hábitos alimentares saudáveis permanentes, através de uma dieta balanceada, principalmente com relação às gorduras e aos carboidratos simples.

\subsubsection{HDL-colesterol}

Na Tabela 6 pode-se observar o efeito das dietas experimentais nos níveis séricos de HDL-C aos 30 e 60 dias de tratamento. 
Tabela 6. Concentração plasmática de HDL-C aos 30 e 60 dias em animais que receberam os tratamentos C.C. (controle caseína), 5\% de maçã, 15\% de maçã e $25 \%$ de maçã.

\begin{tabular}{ccc}
\hline Tratamentos & HDL-C (mg/dL) & HDL-C (mg/dL) \\
& 30 dias & 60 dias \\
\hline C.C. $^{1}$ & $22.45^{2} \pm 0.9^{\mathrm{a} 3}$ & $22.74 \pm 1.3^{\mathrm{a}}$ \\
$5 \%$ de maçã & $22.67 \pm 0.9^{\mathrm{a}}$ & $22.14 \pm 1.3^{\mathrm{a}}$ \\
$15 \%$ de maçã & $22.87 \pm 1.3^{\mathrm{a}}$ & $22.25 \pm 1.3^{\mathrm{a}}$ \\
$25 \%$ de maçã & $24.02 \pm 1.3^{\mathrm{a}}$ & $21.89 \pm 1.3^{\mathrm{a}}$ \\
\hline
\end{tabular}

${ }^{1}$ Sem adição de fibra

${ }^{2}$ Média \pm Desvio padrão de seis animais por tratamento

${ }^{3}$ Médias com letra(s) diferente(s) na vertical diferem estatisticamente ao nível de significância de $\mathrm{p} \leq 0,05$

O grupo C.I. apresentou um nível de 22,60 mg/dL \pm 0,4 de HDL-C sérico, não mostrando diferença significativa com o grupo controle (C.C.). No entanto, esse valor apresentou-se um pouco menor do que o encontrado em ratos normais (19,46 mg/dL), podendo supor que a dieta hipercolesterolêmica, por si, aumenta também o nível do HDL-C. O valor de HDL-C do grupo controle do tempo 30, concordou com o trabalho de Fietz (1998), o qual mostrou um valor de HDL-C de 20,40 mg/dL, nas mesmas condições de dieta e tempo.

Apesar de não haver diferenças significativas entre todos os tratamentos e o controle, as dietas com 5\% e 15\% de maçã, apresentaram aos 30 dias um aumento de $0,9 \%$ e $1,9 \%$, respectivamente, e a dieta com $25 \%$ de maçã foi a que mais se destacou mostrando um aumento de 7\%, em relação ao controle, aos 30 dias. Na Figura 4 pode-se observar com mais clareza, principalmente, a influência da dieta 25\% de maçã no aumento do HDL-C. 


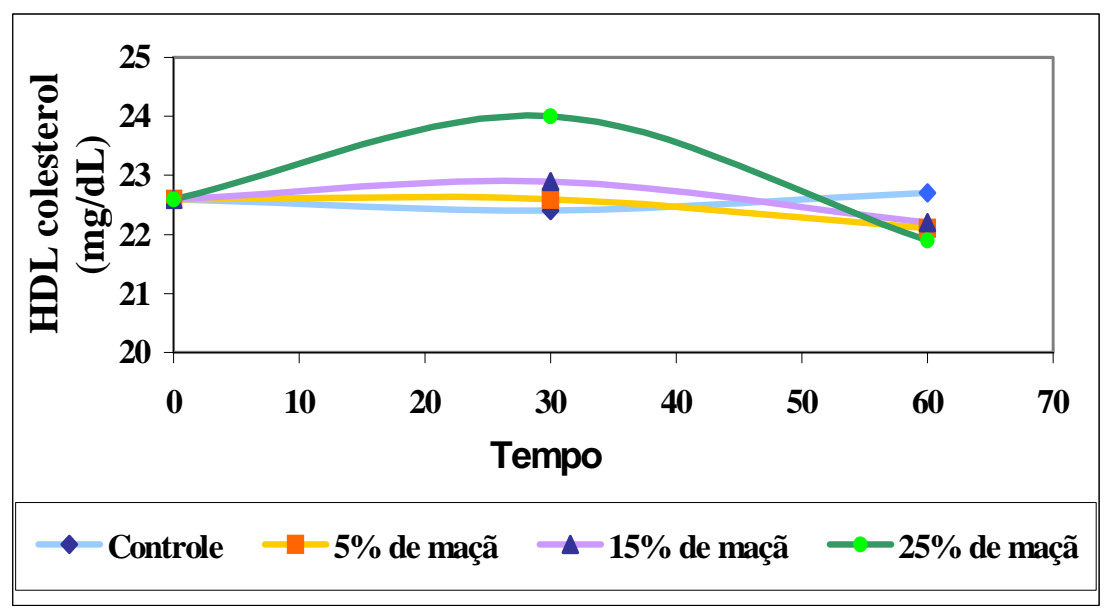

Figura 4 - Níveis séricos de HDL- colesterol (mg/dL) em ratos machos Wistar durante os 60 dias de ensaio biológico.

No estudo de Leontowicz et al. (2002) foi observada uma redução não significativa, de 1,2\% nos níveis sanguíneos de HDL-C em animais que receberam uma dieta hipercolesterolêmica contendo $10 \%$ de maçã durante 28 dias. E na pesquisa de Leontowicz et al. (2001), os autores observaram uma redução de 0,6\% nos níveis de HDL-C em ratos alimentados com uma dieta com 10\% de maçã por 40 dias. Esses trabalhos discordam dos resultados da presente pesquisa, a qual, por apresentar elevações nos níveis de HDL-C, em todas as dietas, pode-se considerar que esses resultados foram efetivos na redução do risco de doenças cardiovasculares.

O aumento do HDL-C no sangue dos animais alimentados com as dietas contendo maçã, principalmente 25\% de maçã, aos 30 dias, embora não significativo, é de fundamental importância, visto que um alto nível sérico de HDL-C é considerado, em vários estudos epidemiológicos e clínicos, como um fator protetor no desenvolvimento de doenças cardiovasculares (Magalhães et al., 2002).

Aos 60 dias, é importante ressaltar que, assim como ocorreu com o colesterol total, os níveis de HDL-C, também tiveram seus níveis semelhantes aos iniciais. 


\subsubsection{LDL-colesterol}

Na Tabela 7 pode-se observar o efeito das dietas experimentais nos níveis séricos de LDL-C aos 30 e 60 dias de tratamento.

Tabela 7. Concentração plasmática de LDL-C aos 30 e 60 dias em animais que receberam os tratamentos C.C. (controle caseína), 5\% de maçã, 15\% de maçã e 25\% de maçã.

\begin{tabular}{ccc}
\hline Tratamentos & $\begin{array}{c}\text { LDL-C (mg/dL) } \\
30 \text { dias }\end{array}$ & $\begin{array}{c}\text { LDL-C (mg/dL) } \\
60 \text { dias }\end{array}$ \\
\hline C.C. ${ }^{1}$ & $52,87^{2} \pm 2,1^{\text {a3 }}$ & $54,41 \pm 1,9^{\mathrm{a}}$ \\
$5 \%$ de maçã & $52,79 \pm 1,9^{\mathrm{a}}$ & $53,95 \pm 2,7^{\mathrm{a}}$ \\
$15 \%$ de maçã & $37,21 \pm 1,6^{\mathrm{b}}$ & $52,69 \pm 1,3^{\mathrm{a}}$ \\
$25 \%$ de maçã & $35,80 \pm 1,3^{\mathrm{b}}$ & $52,35 \pm 1,8^{\mathrm{a}}$ \\
\hline
\end{tabular}

${ }^{1}$ Sem adição de fibra

${ }^{2}$ Média \pm Desvio padrão de seis animais por tratamento

${ }^{3}$ Médias com letra(s) diferente(s) na vertical diferem estatisticamente ao nível de significância de $\mathrm{p} \leq 0,05$

O nível de LDL-C para o grupo C.I. foi de $54,23 \mathrm{mg} / \mathrm{dL} \pm$ 0,9 não apresentando diferenças significativas para o controle, no entanto mostrou-se altos para ratos normais (31,72 mg/dL).

Em Fietz (1998) o nível de LDL-C no grupo controle, aos 30 dias, foi de 42,86 $\mathrm{mg} / \mathrm{dL}$, aproximando-se do valor de LDL-C encontrado na presente pesquisa. O valor de LDL-C em ratos normais assemelhou-se com o trabalho de Yokozama (2002) encontrando 25,7 mg/dL de LDL-C sérico.

No tempo 30, a dieta com 5\% de maçã não apresentou resultados significativos, nos níveis de LDL-C em ratos, com relação ao grupo controle, indicando que essa concentração de maçã pode ser considerada baixa para promover qualquer alteração nos 
níveis de LDL-C. No entanto, nos animais que consumiram dietas com 15\% e 25\% de maçã, observou-se uma redução significativa de 29,6\% e 32,3\%, respectivamente, quando comparados com o grupo controle. Na Figura 6 nota-se as reduções nos níveis de LDL-C provocada pelas dietas com 15\% e 25\% de maçã.

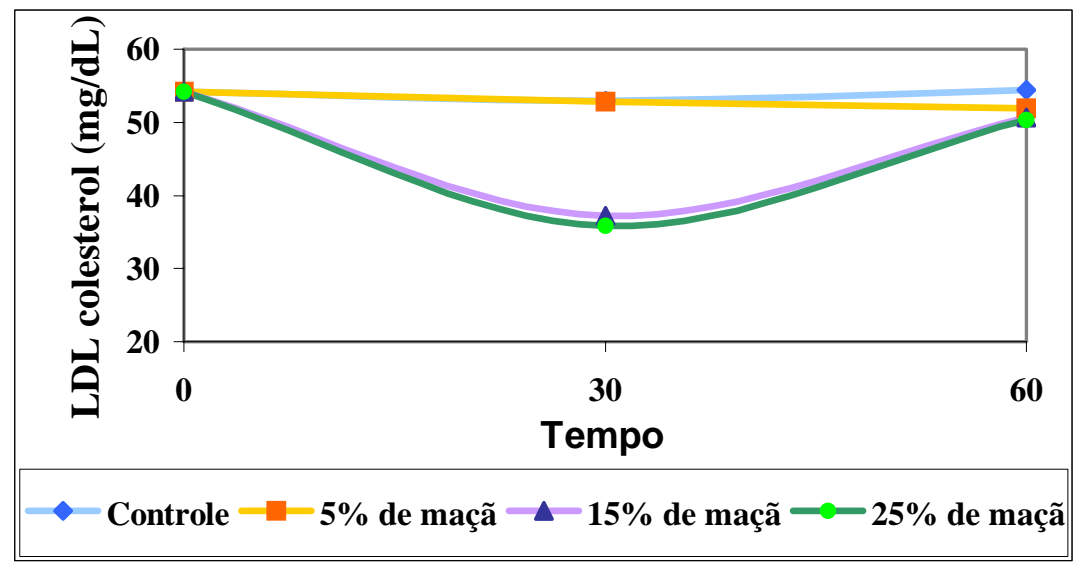

Figura 5 - Níveis séricos de LDL-colesterol (mg/dL) em ratos machos Wistar durante os 60 dias de ensaio biológico.

No estudo de Leontowicz et al. (2002) constataram uma redução de 33\% nos níveis séricos de LDL-C, em ratos alimentados com uma dieta contendo 10\% de maçã, por 28 dias. Esses resultados concordaram com a presente pesquisa, pois foram encontrados em 15\% de maçã uma redução próxima (29,6\%).

Os resultados do estudo de Leontowicz et al. (2001) também podem ser considerados semelhantes aos do presente estudo na redução dos níveis séricos de LDLC na dieta contendo $15 \%$ de maçã. Pois, os pesquisadores obtiveram uma redução significativa de 31\%, forneceram aos ratos uma dieta com 10\% de maçã, por 40 dias.

Segundo Colli et al. (2002), a capacidade de certas fibras, principalmente as fibras solúveis, em reduzir o colesterol plasmático e o nível sérico de LDL-C está bem documentada. A capacidade de formar um composto altamente viscoso no organismo, é a principal característica das fibras solúveis, podendo afetar positivamente o metabolismo de lipídios por meio de muitas vias, incluindo o aumento da excreção de ácidos biliares e a diminuição da absorção de lipídios. 
As dietas com $15 \%$ e $25 \%$ de maçã promoveram reduções significativas tanto nos níveis de colesterol total, como no LDL-C. Isso é muito importante visto que, diversos estudos confirmam que a redução de colesterol total e de LDL representam uma medida eficaz para reduzir a morbidade e a mortalidade cardiovascular, seja no âmbito da prevenção primária, em indivíduos que não mostram sinais de doenças cardiovasculares, seja em pacientes com a doença já estabelecida (Luz \& Cesena, 2001).

A maçã, é considerada como uma das frutas de poder antioxidante, devido aos seus componentes, como a vitamina C e os compostos fenólicos (Cook \& Samman, 1996; Gorinstein et al., 2001; Tomás-Barberán \& Clifford, 2000). Essa capacidade antioxidante é fundamental na prevenção de doenças cardiovasculares, principalmente, devido a prevenção da oxidação da LDL-C, pois a LDL-C oxidada favorece o desenvolvimento da aterosclerose (Ross, 1999).

Entre as dietas contendo maçã e o grupo controle, no tempo 60, não houve alterações significativas (Tabela 7), pode-se, então, observar na Figura 5 que, aos 60 dias, os animais recuperaram os valores iniciais de LDL-C.

\subsubsection{Triglicerídeos}

Na Tabela 8 pode-se observar o efeito das dietas experimentais nos níveis séricos de triglicerídeo aos 30 e 60 dias de tratamento. 
Tabela 8. Concentração plasmática de triglicerídeos aos 30 e 60 dias em animais que receberam os tratamentos C.C. (controle caseína), 5\% de maçã, 15\% de maçã e $25 \%$ de maçã.

\begin{tabular}{ccc}
\hline Tratamentos & $\begin{array}{c}\text { Triglicerídeos (mg/dL) } \\
30 \text { dias }\end{array}$ & $\begin{array}{c}\text { Triglicerídeos (mg/dL) } \\
60 \text { dias }\end{array}$ \\
\hline C.C. $^{1}$ & $84,21^{2} \pm 1,3^{\mathrm{a} 3}$ & $82,30 \pm 1,4^{\mathrm{a}}$ \\
$5 \%$ de maçã & $80,01 \pm 0,2^{\mathrm{b}}$ & $83,28 \pm 0,9^{\mathrm{a}}$ \\
$15 \%$ de maçã & $71,59 \pm 1,4^{\mathrm{c}}$ & $83,34 \pm 1,1^{\mathrm{a}}$ \\
25\% de maçã & $66,10 \pm 0,9^{\mathrm{d}}$ & $82,76 \pm 0,9^{\mathrm{a}}$ \\
\hline
\end{tabular}

${ }^{1}$ Sem adição de fibra

${ }^{2}$ Média \pm Desvio padrão de seis animais por tratamento

${ }^{3}$ Médias com letra(s) diferente(s) na vertical diferem estatisticamente ao nível de significância de $\mathrm{p} \leq 0,05$

O grupo C.I. mostrou níveis de triglicerídeos de $82,53 \mathrm{mg} / \mathrm{dL} \pm 0,8$ não apresentando diferenças significativas para o grupo controle, no entanto mostrou-se altos em relação aos valores de triglicerídeos para ratos normais $(70,38 \mathrm{mg} / \mathrm{dL})$, indicando que a dieta hipercolesterolêmica aumenta, também, os níveis de triglicerídeos.

No estudo de Fietz (1998) foi observado um nível de triglicerídeo de 81,99 $\mathrm{mg} / \mathrm{dL}$ no grupo controle, aos 30 dias de experimento, esse valor foi semelhante ao encontrado na presente pesquisa.

Observa-se na Tabela 8 que, no tempo 30, todas as dietas contendo maçã foram significativamentes diferentes entre si e entre o controle, além de que a redução dos teores de triglicerídeos foi crescente conforme o aumento das concentrações de maçã.

A Figura 6 mostra, com mais clareza, que todas as dietas enriquecidas com maçã foram capazes de reduzir os níveis de triglicerídeos séricos. Os animais consumindo 5\% de maçã apresentaram uma redução de 5,0\%, na dieta contendo 15\% de maçã foi 
observada uma redução de $15 \%$ e naquela contendo $25 \%$ de maçã, a redução foi de 21,5\% nos níveis de triglicerídeos quando comparados com a dieta controle.

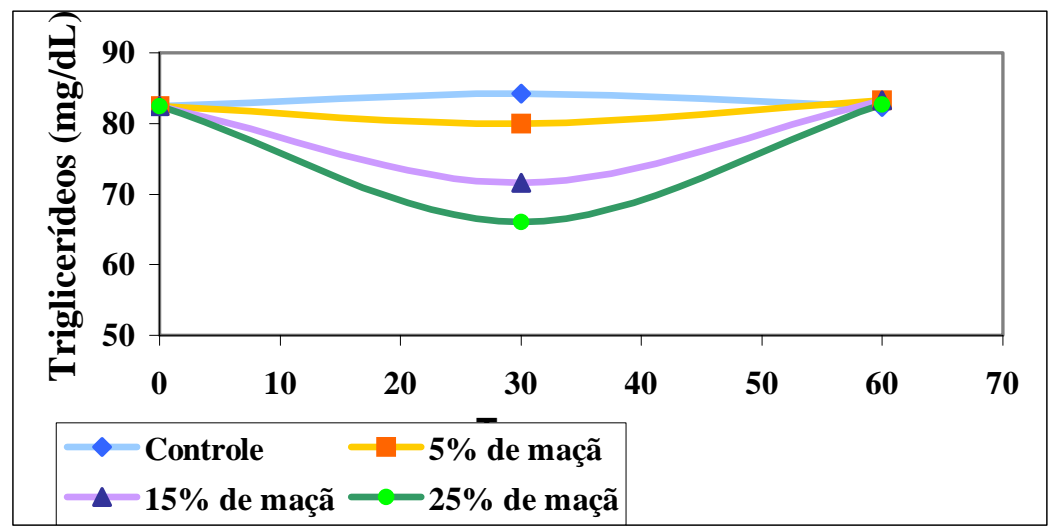

Figura 6 - Níveis séricos de triglicerídeos (mg/dL) em ratos machos Wistar durante os 60 dias de ensaio biológico.

A redução de 15\% observada nos animais que consumiram 15\% de maçã, no presente estudo, concordou com os resultados encontrados por Leontowicz et al. (2001), o qual obteve uma redução de $17 \%$ nos níveis de triglicerídeos em ratos que receberam uma dieta hipercolesterolêmica com 10\% de maçã durante 40 dias. E concordou também com o estudo de Leontowicz et al. (2002), que obteve uma redução de 15\% nos teores de triglicerídeos em ratos hipercolesterolêmicos que consumiram 10\% de maçã, por 28 dias.

No entanto, no estudo de Aprikian et al. (2001) foi observada uma redução de 3,3\% nos níveis séricos de triglicerídeos nos animais que consumiram uma dieta com 15\% de maçã por 21 dias, discordando dos resultados apresentados na presente dissertação.

Os resultados encontrados durante os 30 dias de experimento nas dietas experimentais não se repetiram nos 30 dias seguintes, mostrando-se semelhantes ao grupo controle. Indicando, mais uma vez, uma semelhança com os resultados dos demais parâmetros bioquímicos pesquisados.

O aumento dos níveis de triglicerídeos aos 60 dias pode ser devido a alta concentração de frutose presente nas maçãs. Dai \& McNeill (1992) mostraram que em 
ratos não diabéticos, a suplementação de frutose causou um aumento da pressão arterial, na pulsação e de concentrações de insulina e triglicerídeos.

Davidson et al. (1998) também identificou um aumento nos níveis de triglicerídeos e de colesterol total em humanos que consumiram suco de maçã. Os autores concluíram que, essas alterações lipídicas podem ser parcialmente atribuídas a alta concentração de frutose presente na maçã.

\subsubsection{Colesterol hepático}

Na tabela 9 pode-se observar o efeito das dietas experimentais nos níveis séricos de colesterol hepático aos 30 e 60 dias de tratamento.

Tabela 9. Concentração plasmática de colesterol hepático aos 30 e 60 dias em animais que receberam os tratamentos C.C. (controle caseína), 5\% de maçã, 15\% de maçã e 25\% de maçã.

\begin{tabular}{ccc}
\hline Tratamentos & $\begin{array}{c}\text { Colesterol hepático }(\mathrm{mg} / \mathrm{dL}) \\
30 \text { dias }\end{array}$ & $\begin{array}{c}\text { Colesterol hepático (mg/dL) } \\
60 \text { dias }\end{array}$ \\
\hline C.C. $^{1}$ & $11,76^{2} \pm 1,4^{\text {a3 }}$ & $12,11 \pm 0,9^{\text {a }}$ \\
5\% de maçã & $10,35 \pm 1,4^{\text {a }}$ & $10,90 \pm 1,3^{\text {a }}$ \\
$15 \%$ de maçã & $10,55 \pm 1,1^{\text {a }}$ & $10,79 \pm 1,3^{\text {a }}$ \\
25\% de maçã & $10,09 \pm 1,1^{\text {a }}$ & $10,29 \pm 0,9^{\text {a }}$ \\
\hline
\end{tabular}

${ }^{1}$ Sem adição de fibra

${ }^{2}$ Média \pm Desvio padrão de seis animais por tratamento

${ }^{3}$ Médias com letra(s) diferente(s) na vertical diferem estatisticamente ao nível de significância de $\mathrm{p} \leq 0,05$

O teor de colesterol hepático no grupo C.I. foi de 12,05 mg/dL $\pm 1,4$ não apresentando diferenças significativas para o grupo controle. No entanto mostrou-se altos em relação aos valores de colesterol hepático para ratos normais (9,66 mg/dL). 
No trabalho realizado por Aprikian et al. (2001), o valor de colesterol hepático nos animais do grupo controle, aos 21 dias, foi de 11,2 $\mathrm{mg} / \mathrm{dL}$, muito próximo ao encontrado no presente ensaio biológico.

Conforme observado na Figura 7, todos os animais alimentados com as dietas contendo 5\%, 15\% e 25\% de maçã, apresentaram uma redução nos níveis de colesterol hepático, quando comparados com os animais do grupo controle.

Aprikian et al. (2001), alimentando ratos com 15\% de maçã por 21 dias, observaram uma redução de 9\% no colesterol hepático. Esse estudo concordou com os resultados encontrados na presente pesquisa, no qual uma redução de $10,3 \%$ foi observada nos animais que consumiram uma dieta com 15\% de maçã aos 30 dias.

Em um estudo realizado por Leontowicz et al. (2001) alimentando os ratos, por 40 dias, com uma dieta contendo $10 \%$ de maçã, observaram uma redução de colesterol hepático de 26,3\%. Outro estudo encontrou uma redução de 29,6\% nos níveis de colesterol hepático alimentando ratos com a mesma concentração do estudo anterior, só que por 28 dias, esses resultados discordam do presente estudo por obterem reduções de colesterol hepático maiores do que o observado no presente estudo.

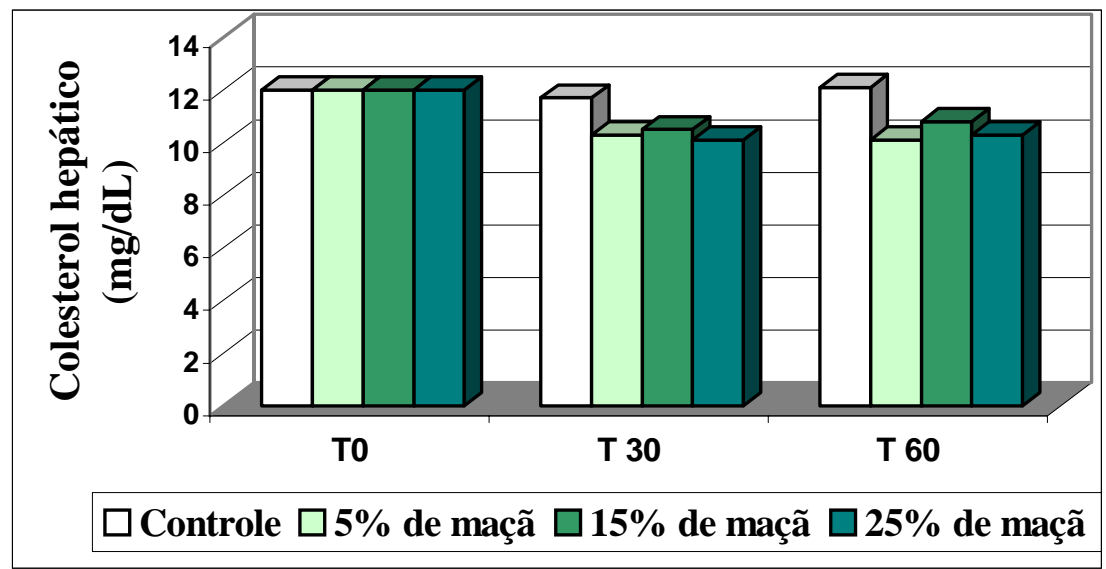

Figura 7 - Níveis de colesterol hepático (mg/dL) em ratos machos Wistar durante os 60 dias de ensaio biológico.

Pode-se notar na Tabela 9 que não foram observadas diferenças significativas entre as dietas contendo maçã e o controle aos 30 e 60 dias. Mas, a análise de variância 
mostrou que apenas o fator tratamento, sem interação com o tempo, foi significativo ao nível de $\mathrm{p} \leq$ 0,01 (Tabela 10). Nas análises bioquímicas anteriores pôde-se analisar a interação do fator tratamento com o fator tempo devido ao fato de serem significantes ao nível de 5\% de probabilidade.

Tabela 10. Análise de variância para colesterol hepático.

\begin{tabular}{cccc}
\hline Causas da Variação & G.L. & Q.M. & PROB.> F \\
\hline Tratamento & 4 & 8,52 & $0,001^{*}$ \\
Tempo & 1 & 1,08 & 0,590 \\
Tratamento*Tempo & 4 & 0,12 & 0,985 \\
Resíduo & 50 & 1,53 & - \\
Total & 59 & - & - \\
\hline
\end{tabular}

* $\mathrm{p} \leq 0,01$ - significante ao nível de $1 \%$ de probabilidade

Logo, o teste de Tukey para médias do fator tratamento no nível de colesterol hepático, está apresentado na Tabela 11.

Tabela 11. Teste de Tukey para médias de tratamento no nível de colesterol hepático.

\begin{tabular}{ccc}
\hline Tratamento & Colesterol hepático $(\mathrm{mg} / \mathrm{dL})$ & $1 \%$ \\
\hline C.I. & 12,05 & $\mathrm{a}^{1}$ \\
C.C. & 11,93 & $\mathrm{a}$ \\
5\% de maçã & 10,67 & $\mathrm{ab}$ \\
15\% de maçã & 10,62 & $\mathrm{ab}$ \\
25\% de maçã & 10,19 & $\mathrm{~b}$ \\
\hline
\end{tabular}

\footnotetext{
${ }^{1}$ Médias com letra(s) diferente(s) diferem estatisticamente ao nível de significância de $\mathrm{p} \leq 0,01$
} 
De acordo com a Tabela 11, verifica-se que a redução nos níveis de colesterol hepático em animais alimentados com 25\% de maçã, foi significativa, independente do tempo.

A redução do colesterol hepático observada principalmente em animais que consumiram uma dieta com 25\% de maçã pode ser devido a alta concentração de fibras, a qual promove uma redução na absorção de sais biliares pelo fígado promovendo a depleção do colesterol que estava armazenado no fígado, como substrato da síntese de novos ácidos biliares perdidos nas fezes (Elhardallou, 1992; Savaiano 2000; Camire \& Dougherty 2003).

Alguns pesquisadores argumentam que produtos da fermentação de bactérias anaeróbicas presentes no intestino a partir de fibras solúveis, podem inibir a síntese do colesterol no fígado, fazendo com que o colesterol armazenado nesse órgão seja utilizado pelo fígado, tanto para a síntese de sais biliares, como para outros fins, como a composição de membranas celulares e hormônios (Corrêa, 2002).

\subsubsection{Colesterol excretado}

Na Tabela 12 pode-se observar o efeito das dietas experimentais nos níveis séricos de colesterol hepático aos 30 e 60 dias de tratamento. 
Tabela 12. Concentração plasmática de colesterol excretado aos 30 e 60 dias em animais que receberam os tratamentos C.C. (controle caseína), 5\% de maçã, 15\% de maçã e $25 \%$ de maçã.

\begin{tabular}{ccc}
\hline Tratamentos & Colesterol excretado (mg/dL) & Colesterol excretado (mg/dL) \\
& 30 dias & 60 dias \\
\hline C.C. ${ }^{1}$ & $90,32^{2} \pm 2,0^{\text {a3 }}$ & $91,33 \pm 0,9^{\text {a }}$ \\
5\% de maçã & $93,35 \pm 1,4^{\text {a }}$ & $93,73 \pm 1,4^{\text {a }}$ \\
$15 \%$ de maçã & $94,63 \pm 1,6^{\text {a }}$ & $94,12 \pm 1,4^{\text {a }}$ \\
25\% de maçã & $94,74 \pm 1,4^{\text {a }}$ & $94,33 \pm 0,9^{\text {a }}$ \\
\hline
\end{tabular}

${ }^{1}$ Sem adição de fibra

${ }^{2}$ Média \pm Desvio padrão de seis animais por tratamento

${ }^{3}$ Médias com letra(s) diferente(s) na vertical diferem estatisticamente ao nível de significância de $\mathrm{p} \leq 0,05$

O valor do grupo C.I. foi de $89,53 \mathrm{mg} / \mathrm{dL} \pm 0,1$, semelhante ao observado no grupo controle em ambos os tempos. O nível de colesterol excretado para o grupo controle do tempo 30 (90,32 mg/dL) foi semelhante ao resultado do estudo de Aprikian et al. (2001) que encontrou 89,27 mg/dL no grupo controle, alimentados por 21 dias.

Analisando a Tabela 12, verifica-se que todos os animais alimentados com as dietas contendo maçã, em ambos os tempos, proporcionaram um aumento, embora não significativos, na excreção de colesterol pelas fezes comparando-se com o controle. No tempo 30, esses aumentos foram, em ordem crescente de concentração de maçã, de $3,4 \% ; 4,8 \%$ e $4,9 \%$, destacando-se as porcentagens de $15 \%$ e $25 \%$ com os maiores aumentos (Figura 8). No tempo 60, a porcentagem de aumento do colesterol excretado foi semelhante entre as dietas: 2,6\% com 5\% de maçã, 3,1\% com 15\% de maçã e 3,3\% com $25 \%$ de maçã. 
Aprikian et al. (2001) também encontraram um aumento no colesterol excretado em animais tratados com 15\% de maçã aos 21 dias, apesar de que nesse estudo o aumento (43\%) foi bem maior que os observados no presente estudo.

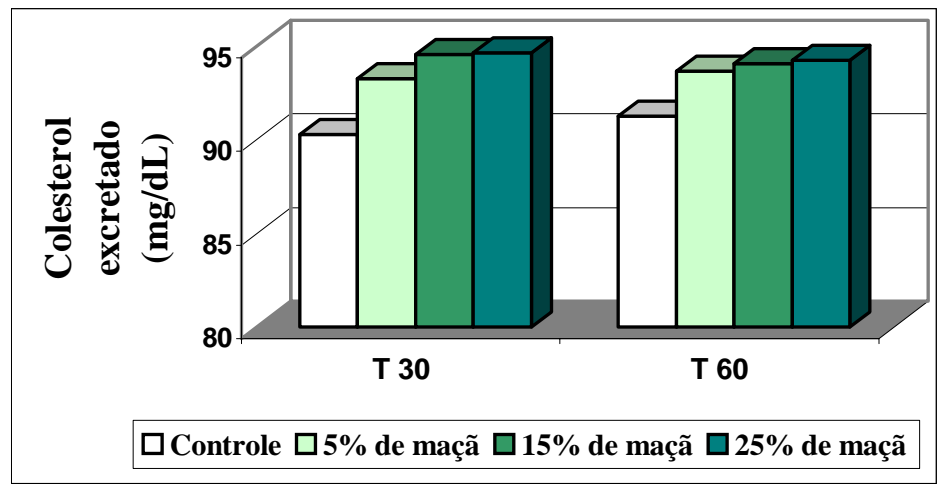

Figura 8 - Níveis de colesterol excretado (mg/dL) em ratos machos Wistar durante os 60 dias de ensaio biológico.

Semelhante ao que ocorreu no colesterol hepático, a análise de variância mostrou que apenas o fator tratamento foi significativo ao nível de probabilidade de $1 \%$, como pode ser observado na Tabela 13.

Tabela 13. Análise de variância para colesterol excretado.

\begin{tabular}{cccc}
\hline Causas da Variação & G.L. & Q.M. & PROB.> F \\
\hline Tratamento & 4 & 60,96 & $0,00001^{*}$ \\
Tempo & 1 & 0,09 & 0,80 \\
Tratamento*Tempo & 4 & 1,17 & 0,57 \\
Resíduo & 50 & 1,59 & - \\
Total & 59 & - & - \\
\hline
\end{tabular}

* p $\leq 0,01$ - significante ao nível de $1 \%$ de probabilidade

Portanto, o teste de Tukey para médias do fator tratamento podem ser observadas na Tabela 14. 
Tabela 14. Teste de Tukey para médias de tratamento no nível de colesterol excretado.

\begin{tabular}{ccc}
\hline Tratamento & Colesterol excretado $(\mathrm{mg} / \mathrm{dL})$ & $1 \%$ \\
\hline C.I. & 89,53 & $\mathrm{a}^{1}$ \\
C.C. & 90,82 & $\mathrm{a}$ \\
5\% de maçã & 93,53 & $\mathrm{a}$ \\
15\% de maçã & 94,37 & $\mathrm{~b}$ \\
25\% de maçã & 94,53 & $\mathrm{~b}$ \\
\hline
\end{tabular}

${ }^{1}$ Médias com letra(s) diferente(s) diferem estatisticamente ao nível de significância de $\mathrm{p} \leq 0,01$

De acordo com a Tabela 14, pode-se verificar que a dieta contendo 5\% de maçã não apresentou diferença significativa em comparação aos grupos controle, no entanto as dietas com 15\% e 25\% de maçã mostraram diferenças significativas em comparação aos controles, mostrando um aumento do nível de colesterol excretado nessas dietas.

As dietas com $15 \%$ e $25 \%$ de maçã foram eficientes em aumentar o colesterol excretado. Esse aumento tem como conseqüência a redução do colesterol sanguíneo e hepático, pois, como demonstram vários estudos, as fibras solúveis, no qual a análise na presente dissertação, mostrou ser maior que a insolúvel, possuem propriedades de impedir a absorção de nutrientes, inclusive de colesterol, na corrente sanguínea, resultando num maior nível de colesterol nas fezes (De Angelis, 2001; Marcil et al. 2002).

Outro aspecto importante que pôde auxiliar no aumento do colesterol excretado, em detrimento da redução do colesterol hepático, é o fato de que as fibras possuem a capacidade de ligar-se irreversivelmente aos ácidos biliares "carregando-os" para as fezes (Savaiano, 2000; Colli et al., 2002). Como os ácidos biliares são compostos de colesterol, a análise feita nas fezes para a quantificação de colesterol pode detectar esse composto. 
Como não há diferenças nos resultados entre as dietas com 15\% e 25\% de maçã, pode-se mencionar que, pelo fato de requerer uma porcentagem menor de maçã, a dieta com 15\% de maçã torna-se a dieta ideal para obter esse resultado. 


\section{CONCLUSÕES}

Do presente trabalho foram propostas as seguintes conclusões:

- A maçã Gala fornece boas fontes de fibras, antioxidantes e microminerais (cobre e ferro);

- A dieta com 25\% de maçã promoveu reduções no ganho de peso e no consumo alimentar em ratos alimentados durante 30 e 60 dias;

- Os efeitos da farinha da maçã sobre os níveis de colesterol total, LDL-C e colesterol excretado foram eficientes nas concentrações de 15\% e 25\% aos 30 dias de experimento. - No que diz respeito aos níveis de HDL-C, nenhuma dieta mostrou alterações significativa aos 30 dias;

- A dieta contendo 25\% de maçã em ratos alimentados por 30 dias, apresentou os melhores resultados quanto aos níveis de triglicerídeos e colesterol hepático;

- Ao final dos 60 dias de experimento, as dietas contendo maçã não foram efetivas na redução dos níveis séricos de colesterol total, HDL-C, LDL-C e triglicerídeos.

\subsection{Considerações finais}

Uma dieta rica em frutas, verduras e legumes, ao longo do tempo, é fundamental para a manutenção da boa saúde. Por isso, a educação nutricional, deve ser incentivada, o quanto antes, em todas as faixas etárias, tanto no consumo desses alimentos como na melhor maneira de prepará-los.

O consumo de maçã, assim como das frutas em geral, possuem propriedades muito estudadas e seus efeitos benéficos comprovados no que diz respeito às doenças não transmissíveis. Entretanto, nenhum alimento pode ser considerado como responsável 
isolado pela manutenção da saúde, pois a dieta é um dos aspectos para se obter uma vida saudável ausente de doenças.

Portanto, bons hábitos alimentares permanentes devem estar sempre acompanhados de hábitos de vida saudáveis como a prática de exercícios físicos, o hábito de não fumar, a redução do estresse, a manutenção do peso corpóreo ideal e outras atitudes positivas para o corpo e a mente. 


\section{REFERÊNCIAS BIBLIOGRÁFICAS}

ALMEIDA, M.E.M. de. Estudo de interações entre o emprego de compostos químicos com o tratamento térmico no controle da atividade da polifenol oxidase em frutas e hortaliças. Piracicaba, 1991. 112p. Dissertação (Mestrado) - Escola Superior de Agricultura "Luiz de Queiroz", Universidade de São Paulo.

ALMEIDA, S. de S.; NASCIMENTO, P.C.B.D.; QUAIOTI, T.C.B. Quantidade e qualidade de produtos alimentícios anunciados na televisão brasileira. Revista de Saúde Pública, v.36, n.3, p.353-355, 2002.

ANDERSEN, J.M.; TURLEY, S.D.; DIETSCHY, J.M. Relative rates of sterol synthesis in the liver and various extrahepatic tissues of normal and cholesterol-fed rabbits. Biochimica et Biophysica Acta (BBA). Lipids and Lipid Metabolism, v.711, n.3, p.421-430, June 1982.

APRIKIAN, O.; BUSSEROLLES, J.; MANACH, C. et al. Lyophilized apple counteracts the development of hypercholesterolemia, oxidative stress, and renal dysfunction in obese Zucker rats. The Journal of Nutrition, v.132, n.7, p.19691976, July 2002.

APRIKIAN, O.; DUCLOS, V.; GUYOT, S. et al. Apple pectin and a polyphenol-rich apple concentrate are more effective together than separately on cecal fermentations and plasma lipids in rats. The Journal of Nutrition, v.133, n.6, p.1860-1865, June 2003. 
APRIKIAN, O.; LEVRAT-VERNY, M-A; BESSON, C. et al. Apple favourably affects parameters of cholesterol metabolism and of anti-oxidative protection in cholesterol fed rats. Food Chemistry, v.75, n.4, p.445-452, 2001.

ASP, N.G.; JOHANSSON, C.G.; HALLMER, H. et al. Rapid enzymatic assay of insoluble and soluble dietary fiber. Journal of Agricultural Food Chemistry, v.31, n.3, p.476-482, May 1983.

ASSOCIATION OFFICIAL ANALYTICAL CHEMISTS. Official methods of analysis. 16.ed. Washington: AOAC, 1975. 1018p.

BAZZANO, L.A.; HE, J.; OGDEN, L. et al. Dietary fiber intake and reduced risk of coronary Herat disease in US men and women. Archives of Internal Medicine, v.163, n.16, p.1897-1904, Sep. 2003.

BAZZANO, L.A.; HE, J.; OGDEN, L.G. et al. Fruit and vegetable intake and risk of cardiovascular disease in US adults: the first National Health and Nutrition Examination Survey Epidemiologic Follow-up Study. The American Journal of Clinical Nutrition, v.76, n.1, p.93-99, July 2002.

BERTASSO, B.A. O consumo alimentar em regiões metropolitanas brasileiras análise da pesquisa de orçamentos familiares. Piracicaba, 2000. 109p. Dissertação (Mestrado) - Escola Superior de Agricultura “Luiz de Queiroz”, Universidade de São Paulo.

BIANCHI, M. de L.P.; RUZ, M.; FRANCESCATTO, H.D.C. et al. Minerais. In: TIRAPEGUI, J. Nutrição: fundamentos e aspectos atuais. São Paulo: Atheneu, 2000. cap.6, p.77-88. 
BOBEK, P.; OZDÍN, L.; HROMADOVÁ, M. The effect of dried tomato, grape and apple pomace on the cholesterol metabolism and antioxidative enzymatic system in rats with hypercholesterolemia. Nahrung, v.42, n.5, p.317-320, 1998.

BRASIL. Ministério da Saúde. DataSUS. http://www.datasus.gov.br (04 nov. 2002).

BROWN, L.; ROSNER, B.; WILLETT, W.W. et al. Cholesterol-lowering effects of dietary fiber: a meta-analysis. The American Journal of Clinical Nutrition, v.69, n.1, p.30-42, 1999.

CAMIRE, M.E.; DOUGHERTY, M.P. Raisin dietary fiber composition and in vitro bile acid binding. Journal of Agricultural and Food Chemistry, v.51, n.3, p.834-837, 2003.

CARAMELLI, B. Avaliação do risco cardiovascular. In: BRASIL. Ministério da Saúde; Universidade de São Paulo; Instituto para o Desenvolvimento da Saúde. Manual de condutas médicas. Brasília, 2002. 490p. (Série A. Normas e Manuais Técnicos, 143)

CARVALHO, G.F. de. Consumo de frutas: um estudo exploratório. Piracicaba, 1998. 229p. Dissertação (Mestrado) - Escola Superior de Agricultura "Luiz de Queiroz", Universidade de São Paulo.

COLLI, C.; SARDINHA, F.; FILISETTI, T.M.C.C. Alimentos funcionais. In: SCHOR, N. (Coord.); CUPPARI, L. (Ed.). Guia de nutrição: nutrição clínica no adulto. São Paulo: Manole, 2002. cap.4, p.55-70.

COMBS, G.F. Jr. The vitamins fundamental aspects in nutrition and health. 2.ed. San Diego: Academic Press, 1998. 618p. 
COOK, N.C.; SAMMAN, S. Flavonoids-chemistry, metabolism, cardioprotective effects, and dietary sources. Journal of Nutritional Biochemistry, v.7, n.2, p.66-76, Feb. 1996.

CORRÊA, A.D. Fibras na prevenção de doenças. Lavras: UFLA/FAEPE, 2002. 43p.

COSTA, R.P.; MENENDEZ, G.; BRICARELLO, L.P. et al. Óleo de peixe, fitosteróis, soja e antioxidantes: impacto nos lípides e na aterosclerose. Revista da Sociedade de Cardiologia do Estado de São Paulo, v.10, n.6, p.819-827, 2000.

DABBAGH, A.J.; SHWAERY, G.T.; KEANEY, J.F. et al. Effect of iron overload and iron deficiency on atherosclerosis in the hypercholesterolemic rabbits. Arteriosclerosis, Thrombosis, and Vascular Biology, v.17, p.2638-2645, Nov. 1997.

DAI, S.; MCNEILL, J.H. Effects of fructose loading in streptozotocin-diabetic and nondiabetic rats. Canadian Journal Physiology and Pharmacology, v.70, p.15831589, 1992.

DAI, S.; TODD, M.E.; LEE, S. et al. Fructose loading induces cardiovascular and metabolic changes in nondiabetic and diabetic rats. Canadian Journal Physiology and Pharmacology, v.72, p.771-781, 1994.

DAVIDSON, M.H.; DUGAN, L.D.; STOCKI, J. et al. A low-viscosity soluble-fiber fuit juice supplement fails to lower cholesterol in hypercholesterolemic men and women. The Journal of Nutrition, v.128, n.11, p.1927-1932, 1998.

DAVIES, M.B.; AUSTIN, J.; PARTRIDGE, D.A. Vitamin C: its chemistry and biochemistry. Cambridge: Royal Society of Chemistry, 1991. 154p. 
DE ANGELIS, R.C. Importância de alimentos vegetais na proteção da saúde: fisiologia da nutrição protetora e preventiva de enfermidades degenerativas. São Paulo: Atheneu, 2001. 295p.

DREHER, M.L. Handbook of dietary fiber. New York: Marcel Dekker, 1987. 468p.

ELHARDALLOU, S.B. The bile acids binding of the fibre-rich fractions of three starchy legumes. Plant Food for Human Nutrition, v.42, p.207-218, 1992.

ELKINS, E.R.; MATTHYS, A.; LYON, R. et al. Characterization of commercially produced apple juice concentrate. Journal of Composition and Analysis, v.9, n.1, p.43-56, Mar. 1996.

FAO. Tabla de composición de alimentos de America Latina. http://www.rlc.fao.org/bases/alimento (29 Sep. 2003)

FIETZ, V.R. Efeitos da pectina cítrica de alta e baixa metoxilação e da celulose nos níveis séricos de colesterol e triglicerídeos em ratos hiperlipidêmicos. Piracicaba, 1998. 60p. Dissertação (Mestrado) - Escola Superior de Agricultura "Luiz de Queiroz", Universidade de São Paulo.

FNP CONSULTORIA \& AGROINFORMATIVOS. Agrianual 2003: anuário da agricultura brasileira. São Paulo, 2003. p.370-377: Maçã.

FNP CONSULTORIA \& COMÉRCIO. Agrianual 2002: anuário da agricultura brasileira. São Paulo, 2002. p.370-380: Maçã.

FONTOURA, P.S.G.; FREITAS, R.J.S. de. Características sensoriais de algumas variedades de maçã cultivadas no Brasil. Boletim CEPPA, v.11, n.2, p.131-138, 1993. 
FORNÉS, N.S.; MARTINS, I.S.; HERNAN, M. et al. Food frequency consumption and lipoproteins serum levels in the population of an urban area, Brazil. Revista de Saúde Pública, v.34, n.4, p.380-387, 2000.

FRANCO, G. Tabela de composição química de alimentos. 8.ed. São Paulo: Atheneu, 1992. 230p.

FRANTZ, I.D.; SCHNEIDER, H.S.; HINKELMAN, B.T. Supression of hepatic cholesterol synthesis in the rat by cholesterol feeding. Journal of Biological Chemistry, v.206, n.1, p.465-469, Jan. 1954.

FRIEDEWALD, W.T.; LEVY, R.I.; FREDRICKSON, D.S. Estimation of the concentration of low-density lipoprotein cholesterol in plasma, without use of the preparative ultracentrifuge. Clinical Chemistry, v.18, n.6, p.499-502, June 1972.

GOMES, S.M. Efeitos de flavonóides no metabolismo lipídico. Viçosa, 1998. 95p. Dissertação (M.S.) - Universidade Federal de Viçosa.

GONÇALVES, J.S.; AMARO, A.A.; MAIA, M.L.; SOUZA, S.A.M. Produção, mercado e inserção internacional da maçã brasileira. Agricultura em São Paulo, v.43, n.1, p.95-136, 1996.

GONZÁLEZ, M.; RIVAS, C.; CARIDE, B.; LAMAS, M.A.; TABOADA, M.C. Effects of orange and apple pectin on cholesterol concentration in serum, liver and faeces. Journal of Physiology Biochemistry, v.54, n.2, p.99-104, 1998.

GORINSTEIN, S.; ZACHWIEJA, Z.; FOLTA, M. et al. Comparative contents of dietary fiber, total phenolics, and minerals in persimmons and apples. Journal of Agricultural Food Chemistry, v.49, n.2, p.952-957, Feb. 2001. 
GRUDEVA-POPOVA, J.; KRACHANOVA, M.; DJURDJEV, A. et al. Application of soluble dietary fibres in treatment of hyperlipoproteinemias. Folia Medica (Plovdiv), v.39, n.1, p.39-43, 1997.

GUEYAS, F.; BLANKENSHIP, S.M.; YOUNG, E. et al. Dietary fibre content of thirteen apple cultivars. Journal Science of Food Agricultural, v.75, n.3, p.333-340, Nov. 1997.

HAMILTON, J.M.; GILMORE, W.S.; STRAIN, J.J. Marginal copper deficiency and atherosclerosis. Biological Trace Element Research, v.78, n.1-3, p.179-189, 2000.

HARKER, F.R.; GUNSON, F.A.; JAEGER, S.R. The case for fruit quality: an interpretative review of consumer attitudes, and preferences for apples. Postharvest Biology and Technology, v.28, n.3, p.333-347, 2003.

HARRIS, P.J.; TASMAN-JONES, C.; FERGUSON, L.R. Effects of two contrasting dietary fibres on starch digestion, short-chain fatty acid production and transit time in rats. Journal of the Science and Agriculture, v.80, n.14, p.2089-2095, Nov. 2000.

HASLAM, E. Natural polyphenols (vegetable tannins) as drugs and medicines: possible modes of action. Journal of Nature Products, v.59, p.205-215, 1996.

HASLER, C.M. Functional foods: benefits, concerns and challenges: a position paper from the american council on science and health. The Journal of Nutrition, v.132, n.12, p.3772-3781, Dec. 2002.

HAUG, A.; HOSTMARK, A.T. Lipoprotein lipases, lipoproteins and tissue lipids in rats fed fish oil or coconut oil. The Journal of Nutrition, v.117, n.6, p.1011-1017, 1987. 
HERTOG, M.G.; KROMHOUT, D.; ARAVANIS, C. et al. Flavonoid intake and longterm risk of coronary heart disease and cancer in the seven countries study. Archives of Internal Medicine, v.155, n.4, p.381-386, 1995.

HU, F.B. Plant-based foods and prevention of cardiovascular disease: an overview. The American Journal of Clinical Nutrition, v.78, n.3, p.544-551, Sep. 2003. Supplement.

INSTITUTO BRASILEIRO DE GEOGRAFIA E ESTATÍSTICA (IBGE). Pesquisa de orçamentos familiares 1995-1996. Rio de Janeiro, 1998. v.2.

JACQMAIN, M.; DOUCET, E.; DESPRÉS, J.-P. et al. Calcium intake, body composition, and lipoprotein-lipid concentrations in adults. The American Journal of Clinical Nutrition, v.77, n.6, p.1448-1452, June 2003.

JAMES, S.L.; MUIR, J.G.; CURTIS, S.L. et al. Dietary fibre: a roughage guide. Internal Medicine Journal, v.33, n.11, p.291-296, Nov. 2003.

JOHNSEN, S.P.; OVERVAD, K.; STRIPP, C. et al. Intake of fruit and vegetables and risk of ischemic stroke in a cohort of danish men and women. The American Journal of Clinical Nutrition, v.78, n.1, p.57-64, July 2003.

JORGE, Z.L.C.; TREPTOW, R.O.; ANTUNES, P.L. Avaliação físico-química e sensorial de suco de maçãs cultivares Fuji, Granny Smith e seus "blends". Revista Brasileira de Agrociência, v.4, n.1, p.15-19, 1998.

JOSHI, V.K.; SANDHU, D.K. Preparation and evaluation of an animal feed byproduct produced by solid-state fermentation of apple pomace. Bioresource Technology, v.56, n.2-3, p.251-255, May/June 1996. 
KIECHL, S.; WILLEIT, J.; EGGER, G. et al. Body iron stores and the risk of carotid atherosclerosis: prospective results from the Bruneck study. Circulation, v.96, n.18, p.3300-3307, Nov. 1997.

LAMPE, J. Health effects of vegetable and fruit: assessing mechanisms of action in human experimental studies. The American Journal of Clinical Nutrition, v.70, n.3, p.475-490, Sep. 1999. Supplement.

LEEDES, A.R.; HUSSAIN, K. A review of the effects of dietary fiber and their potential benefits of health. International Journal of Food Sciences and Nutrition, v.49, p.58, 1998.

LEJA, M.; MARECZEK, A.; BEN, J. Antioxidant properties of two apple cultivars during long-term storage. Food Chemistry, v.80, n.3, p.303-307, 2003.

LEONTOWICZ, H.; GORINSTEIN, S.; LOJEK, A. et al. comparative content of some bioactive compounds in apples, peaches and pears and their influence on lipids and antioxidant capacity in rats. Journal of Nutrition Biochemistry, v.13, n.10, p.603610, Oct. 2002.

LEONTOWICZ, M.; GORINSTEIN, S.; BARTNIKOWSKA, E. et al. Sugar beet pulp and apple pomace dietary fibers improve lipid metabolism in rats fed cholesterol. Food Chemistry, v.72, n.1, p.73-78, 2001.

LEONTOWICZ, M.; GORINSTEIN, S.; LEONTOWICZ, H. et al. Apple and pear peel and pulp and their influence on plasma lipids and antioxidant potentials in rats fed cholesterol-containing diets. Journal of Agricultural Food Chemistry, v.51, n.19, p.5780-5785, Sep. 2003. 
LIU, J.-C.; HSU, F.-L.; TSAI, J.-C. et al. Antihypertensive effects of tannins isolated from traditional chinese herbs as non-specific inhibitors of angiontensin converting enzyme. Life Sciences, v.73, n.12, p.1543-1555, 2003.

LIU, R.H. Health benefits of fruit and vegetables are from additive and synergistic combinations of phytochemicals. The American Journal of Clinical Nutrition, v.78, n.3, p.517-520, Sep. 2003. Supplement.

LIU, S.; MANSON, J.E.; LEE, I.-M. et al. Fruit and vegetable intake and risk of cardiovascular disease: the women's health study. The American Journal of Clinical Nutrition, v.72, n.4, p.922-928, Oct. 2000.

LUZ, P.L. da; CESENA, F.H.Y. Prevenção da doença coronariana. Revista da Sociedade de Cardiologia do Estado de São Paulo, v.11, n.2, p.vi-Xx, 2001.

MACHEIX, J.-J.; FLEURIET, A.; BILLOT, J. Fruit phenolics. Florida: CRC Press, 2000. 378p.

MACHLIN, L.J. (Ed.). Handbook of vitamins. 2.ed. New York: Marcel Dekker, 1991. 595p.

MAGALHÃES, C.C.; CHAGAS, A.C.P.; LUZ, P.L. da. Importância do HDL-colesterol como preditor de risco para eventos cardiovasculares. Revista da Sociedade de Cardiologia do Estado de São Paulo, v.12, n.4, p.560-568, 2002.

MAHAN, L.K. Krause: alimentos, nutrição \& dietoterapia. 9.ed. São Paulo: Roca, 1998. 1179p. 
MARANHÃO, R.C. Efeito do colesterol alimentar no metabolismo corpóreo de colesterol: comparação entre indivíduos normais e hipercolesterolêmicos. São Paulo, 1981. 51p. Tese (Doutorado) - Instituto de Ciências Biomédicas, Universidade de São Paulo.

MARCIL, V.; DELVIN, E.; SEIDMAN, E. et al. Modulation of lipid síntesis, apolipoprotein biogenesis, and lipoprotein assembly by butyrate. American Journal of Physiology: Gastrointestinal and Liver Physiology, v.283, p.G340-G346, 2002.

MARLETT, J.A.; MCBURNEY, M.I.; SLAVIN, J.L. Health implications of dietary fiber. Journal of the American Dietetic Association, v.102, n.7, p.993-1000, 2002.

MARTINEZ, T.L. da R. (Ed.). Condutas clínicas nas dislipidemias. Belo Horizonte: Health, 1997. 291p.

MAZUR, W.M.; DUKE, J.A.; WAHALA, K. et al. Isoflavonoids and lignans in legumes: nutritional and health aspects in humans. The Journal of Nutritional Biochemistry, v.9, n.4, p.193-200, 1998.

MC NAMARA, D.J. Dietary cholesterol and atherosclerosis. Biochimica et Biophysica Acta (BBA). Molecular and Cell Biology of Lipids, v.1529, n.1-3, p.310-320, Dec. 2000.

MENDES, A.C.; DAVID, P.R. de B.S.; ALBINO, E. Atividade enzimática das polifenolxidases em polpa de maçãs: o efeito da adição de metabissulfito de sódio como agente inibidor. Higiene alimentar, v.13, n.63, p.32-36, 1999.

MENDEZ, M.H.M.; DERIVI, S.C.N.; RODRIGUES, M.C.R. et al. Tabela de composição de alimentos. Rio de Janeiro: EDUFF, 2001. 41p. 
MILLER, N.J.; DIPLOCK, A.T.; RICE-EVANS, C.A. Evaluation of the total antioxidant activity as a marker of the deterioration of apple juice on storage. Journal of Agricultural Food Chemistry, v.43, n.7, p.1794-1801, July 1995.

MORIGUCHI, E.H. Relação LDL/HDL e risco cardiovascular: perspectivas na avaliação do risco coronariano: do empirismo à estimação matemática. s.n.t.

MOUNDRAS, C.; BEHR, S.R.; RÉMÉSY, C. et al. Fecal losses of sterols and bile acids induced by feeding rats guar gum are due to greater pool size and liver bile acid secretion. The Journal of Nutrition, v.127, n.6, p.1068-1076, June 1997.

OLIVEIRA, M.C. de; SICHIERI, R.; MOURA, A.S. Weight loss associated with a daily intake of three apples or three pears among overweight women. Nutrition, v.19, n.3, p.253-256, 2003.

ORLOV, M.V.; BRODSKY, M.A.; DOUBAN, S. A review of magnesium, acute myocardial infarction and arrhythmia. Journal of the American College of Nutrition, v.13, n.2, p.127-132, Apr. 1994.

PANAGIOTAKOS, D.B.; PITSAVOS, C.; KOKKINOS, P. et al. Consumption of fruits and vegetables in relation to the risk of developing acute coronary syndromes: the CARDIO2000 case-control study. Nutrition Journal, v.2, 2003. http://www.nutritionj.com/content/2/1/2 (14 Nov. 2003)

PEARSON, D.A.; TAN, C.H.; GERMAN, J.B.; DAVIS, P.A.; GERSHWIN, M.E. Apple juice inhibits human low density lipoprotein oxidation. Life Sciences, v.64, n.21, p.1913-1920, 1999. 
PEREIRA, W.L. Efeito hipolipidêmico de flavonóides, corantes naturais e suas associações. Viçosa, 1999. 138p. Dissertação (M.S.) - Universidade Federal de Viçosa.

PHILIPPI, S.T. Tabela de composição de alimentos: suporte para decisão nutricional. Brasília: ANVISA/FINATEC/UNB, NUT, 2001. 133p.

PIEDADE, J.; CANNIATTI-BRAZACA, S.G. Comparação entre o efeito do resíduo do abacaxizeiro (caules e folhas) e da pectina cítrica de alta metoxilação no nível de colesterol sanguíneo em ratos. Ciência e Tecnologia de Alimentos, v.23, n.2, p.149156, 2003.

PINHEIRO, A.B.; LACERDA, E.M. de A.; BENZECRY, E.H. et al. Tabela para avaliação de consumo alimentar em medidas caseiras. 3.ed. Rio de Janeiro, 1993. $75 p$.

PLAAMI, S.P. Content of dietary fiber in foods and its physiological effects. Food Reviews International, v.13, n.1, p.29-76, 1997.

PREGNOLATTO, W.; PREGNOLATTO, N.P. (Coord.). Normas analíticas do Instituto Adolfo Lutz. 3.ed. São Paulo: Instituto Adolfo Lutz, 1985. 578p.

PRICE, M.L.; SCOYOC, S.V.; BUTLER, L.G. A critical evaluation of the vanillin reaction as an assay for tannin in sorghum grain. Journal of Agricultural Food Chemistry, v.26, n.5, p.1214-1218, 1978.

PROTZEK, E.C.; FREITAS, R.J.S. de; WASCZYNSKJ, N. Aproveitamento do bagaço de maçã na elaboração de biscoitos ricos em fibra alimentar. Boletim CEPPA, v.16, n.2, p.263-275, 1998a. 
PROTZEK, E.C.; FREITAS, R.J.S. de; WASCZYNSKJ, N. Incorporação de fibra do bagaço de maçã em pães de forma. In: LAJOLO, F.M.; MENEZES, E.W. (Ed.). Temas en tecnología de alimentos. México: IPN, 1998b. p.245-257.

QUINTÃO, E.C.R.; GRUNDY, S.M.; AHRENS, E.H. Jr. Effects of dietary cholesterol on the regulation of total body cholesterol in man. Journal of Lipid Research, v.12, n.2, p.233-247, Mar. 1971.

REEVES, P.G.; NIELSEN, F.H.; FAHEY, G.C. AIN-93: purified diets for laboratory rodents: final report of the american institute of nutrition ad hoc writing committee on the reformulation of the AIN-76A Rodent Diet. The Journal of Nutrition, v.123, n.11, p.1939-1951, 1993.

ROBARDS, K.; PRENZLER, P.D.; TUCKER, G.; SWATSITANG, P.; GLOVER, W. Phenolic compounds and their role in oxidative processes in fruits. Food Chemistry, v.66, n.4, p.401-436, Sep. 1999.

ROSA, C. de O.B. Propriedade do feijão (Phaseolus vulgaris L.) na redução do colesterol sanguíneo em ratos hipercolesterolêmicos. Viçosa, 1996. 80p. Dissertação (M.S.) - Universidade Federal de Viçosa.

ROSS, R. Patogênese da aterosclerose. In: BRAUNWALD, E. (Ed.). Tratado de medicina cardiovascular. 5.ed. São Paulo: Roca, 1999. cap.14, p.1179-1198.

ROSSI, E.A. Alimentos funcionais. In: DÂMASO, A. (Coord.). Nutrição e exercício na prevenção de doenças. Rio de janeiro: MEDI, 2001. cap.14, p.337-362. 
SANTOS, R.D. (Coord.). III Diretrizes brasileiras sobre dislipidemias e diretriz de prevenção da aterosclerose do Departamento de Aterosclerose da Sociedade Brasileira de Cardiologia. Arquivos Brasileiros de Cardiologia, v.77, p.1-48, nov. 2001. Suplemento, 3.

SARRUGE, J.R.; HAAG, H.P. Análises químicas em plantas. Piracicaba: ESALQ, Depto. Química, Setor Nutrição Mineral de Plantas, 1974. 56p.

SAVAIANO, D.A. Cardiovascular disease and fiber: is insulin resistance the missing link? Nutrition Reviews, v.58, n.11, p.356-358, 2000.

SHAHIDI, F.; NACZK, M. Food phenolics: an overview. In: SHAHIDI, F.; NACZK, M. (Ed.). Food phenolics: sources, chemistry, effects, applications. Lancaster: Technomic, 1995. p.1-5.

SWAIN, T.; HILLIS, W.E. The phenolic constituents of Prunus domestica I. The quantitative analysis of phenolic constituents. Journal Science of Food Agricultural, v.10, p.63-68, Jan. 1959.

TAHVONEN, R. Contents of selected elements in some fruits, berries, and vegetables on the finnish market in 1987-1989. Journal of Food Composition and Analysis, v.6, n.1, p.75-86, Mar. 1993.

THE NATIONAL ACADEMIES. Dietary Reference Intake (DRI). http://www.lap.nap.edu/nap-cgi/discover.cgi?term=dri\&restric=nap (29 Sep. 2003)

TIJBURG, L.B; MATTERN, T.; FOLTS, J.D. et al. Tea flavonoids and cardiovascular disease: a review. Critical Reviews in Food Science and Nutrition, v.37, p.771785, 1997. 
TOMÁS-BARBERÁN, F.A.; CLIFFORD, M.N. Flavanones, chalcones and dihydrochalcones-nature, occurrence and dietary burden. Journal Science of Food Agricultural, v.80, n.7, p.1073-1080, May 2000.

TREPTOW, R. de O.; QUEIROZ, M.I.; ANTUNES, P.L. Caracterização físico-química e sensorial de quatro cultivares de maçãs (Malus domestica Borkh). Revista Brasileira de Agrociência, v.1, n.3, p.179-184, 1995.

TSUJI, H.; VENDITTI, F.J. Jr.; EVANS, J.C. et al. The association of level of serum potassium and magnesium with ventricular premature complexes (The Framingham heart study). The American Journal of Cardiology, v.74, p.232-235, 1994.

TURANO, W.; ALMEIDA, C.C.C. Educação nutricional. In: GOUVEIA, E.L.C. Nutrição: saúde \& comunidade. Rio de Janeiro: Revinter, 1999. cap. 3, p.57-77.

UNITED STATES DEPARTMENT OF AGRICULTURE (USDA). Nutrient data laboratory. http://www.nal.usda.gov/fnic/foodcomp/ (29 Sep. 2003)

UNIVERSIDADE DE SÃO PAULO. Departamento de Alimentos e Nutrição Experimental. Tabela brasileira de composição de alimentos. http://www.fcf.usp.br (29 set. 2003)

USHIROZAWA, K. Cultura da maçã: a experiência catarinense. Florianópolis: EMPASC, 1978. 295p.

VALE, A.A.L.; MARTINEZ, T.L.R. Fatores de risco coronário: quais os já consagrados e sus importância na gênese da doença coronária? In: TIMERMAN, A.; CÉSAR, L.A.M. (Ed.). Manual de cardiologia. São Paulo: Atheneu, 2000. cap.20, p.99-102. 
VASKONEN, T. Dietary minerals and modification of cardiovascular risk factors. Journal of Nutrition Biochemistry, v.14, n.9, p.492-506, Sep. 2003.

VINSON, J.A.; SU, X.; ZUBIK, L.; BOSE, P. Phenol antioxidant quantity and quality in foods: fruits. Journal of Agricultural Food Chemistry, v.49, n.11, p.5315-5321, Nov. 2001.

WANG, H.; CAO, G.; PRIOR, R.L. Total antioxidant capacity of fruits. Journal of Agricultural Food Chemistry, v.44, n.3, p.701-705, Mar. 1996.

WILSKA-JESZKA, J. Proanthocyanidins: content in fruits and influence on health. Food Chemistry, v.57, n.1, p.57-59, 1996. /Resumo/

YOKOZAWA, T.; NAKAGAWA, T.; KITANI, K. Antioxidative activity of green tea polyphenol in cholesterol-fed rats. Journal of Agricultural Food Chemistry, v.50, n.12, p.3549-3552, June 2002.

YURI, H.M.; MARTINES FILHO, J.G. Maçã: preferência do consumidor e regularidade de oferta. Preços Agrícolas, v.14, n.156, p.44-45, 1999.

ZONTA, E.P.; MACHADO, A.A. Programa SANEST: sistema de análise estatística para computadores (software). Pelotas: UFPel, s.d. 